\title{
EVALUATION OF CONVECTIVE HEAT AND MASS TRANSFER COEFFICIENTS FOR DIFFERENT PRODUCTS IN A NEW NATURAL CONVECTION SOLAR DRYER
}

\author{
Sh. Shams El-Din, M. Habib, A. El-Hanafy and Kh. Ramzy \\ Mechanical Power Engineering Department, Faculty of Engineering, \\ Minoufiya University, Shebin El-kom, Egypt \\ E-mailEng_khalidramzy1@yahoo.com
}

\begin{abstract}
The purpose of the present study was to evaluate the Nusselt and Sherwood numbers during the drying of different products in a new conical type natural convection solar dryer. A comparison with the box-type collector-mode solar dryers was done. So, three types of solar dryers were designed and fabricated at Faculty of Engineering-Shebin El-Kom, Minoufiya University, Egypt. The dryers were constructed from materials that are readily available in the local area. The conical solar dryers with cone height to dryer diameter ratios ranged from 0.5 to 2 were tested. The performance of solar dryers was evaluated at the month of July 2009. The range of climatic conditions during the test period varied from $23{ }^{\circ} \mathrm{C}$ to $37{ }^{\circ} \mathrm{C}$ for ambient air temperatures and from $30 \%$ to $55 \%$ for the relative humidity during this test period. The products used in these experiments (grapes, apricots, onions and potatoes) were obtained from the local markets and were cleaned well from dirties before the drying process. The Nusselt and Sherwood numbers were calculated with the aid of both moisture evaporation measurements and Chilton-Colburn analogy.

The results indicated that the highest Nusselt and Sherwood numbers occur for the conical solar dryer with height to dryer diameter ratio of unity. It is also observed that, the values of Nusselt and Sherwood numbers depend upon the drying mode and the product to be dried. In additions, the highest values of the Nusselt and Sherwood numbers were obtained for potato slices compared with the other products. The analogy between heat and mass transfer coefficients was also investigated.

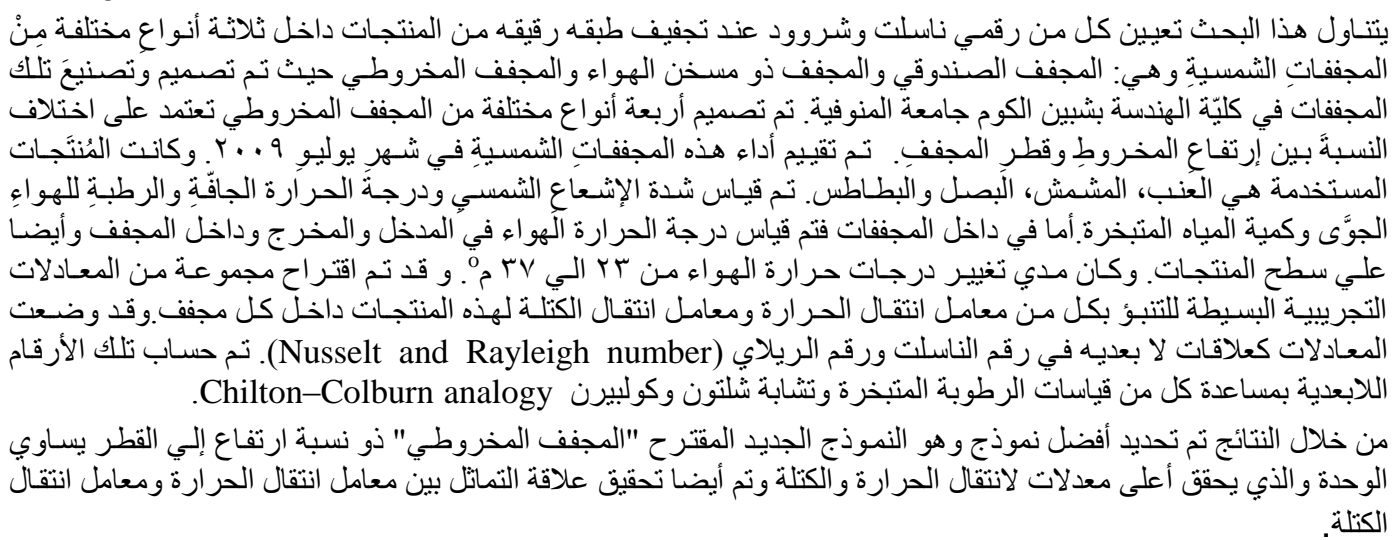

Keywords: Convective heat transfer, mass transfer, products drying, solar dryers.

\section{INTRODUCTION}

Drying is an important method of preservation of wet materials and is applicable to a wide range of industrial and agricultural products, including foodstuffs. Today various methods of drying have been developed for particulate materials, including fluidized-bed and spouted-bed drying techniques [1]. Drying is a continuous process with changes in moisture content, air and product temperatures and the humidity of air all occurring simultaneously. Heat is transferred from the surrounding air and from the sun to the surface of the product in different modes of heat transfer. It is utilized in two ways; i.e. to increase the product temperature in the form of sensible heat and in removal of moisture or, in other terms, mass transfer utilizing the latent heat of 
vaporization $[2,3]$. The convective heat and mass transfer coefficients are important parameters in mathematical modeling and computer simulation of the drying process, since the rate of heat transfer and the rate of drying between the air and product varies with these coefficients. Usually, two methods are available to determine the convective heat transfer coefficient for products. These are dimensional analysis and direct measurement of heat transfer on a product by comparing the temperature curves with Shumann's exact solution [2]. The dimensional analysis is mathematically simple and has a wide range of applications. This method is incomplete without sufficient experimental data, although it facilitates the interpretation and extends the range of experimental data application by correlating them in terms of dimensional groups [3]. However, in most cases the convective heat transfer coefficient is used to determine the mass transfer coefficients [4-5]. Ciesielczyk [6] used the Chilton-Colburn analogy to calculate the interfacial coefficient of heat and mass transfer in a constant rate period of fluidized bed drying. Inazu et al. [7] used the Chilton-Colburn analogy to determine the mass transfer coefficient with known values of the heat transfer coefficient in the process of fresh Japanese noodle upon drying.

There are a lot of researches made on drying products. These researches aimed drying to be achieved in a short time, obtaining a more product quality, describing the process of drying and designing an efficient drying unit. For these purposes, Doymaz [8], different local products, Dinçer and Hussainn [9], products having different geometries, Mabrouk et al. [10], different dryer types, Ismail [11], pretreatments for obtaining quality food, Othman et al. [12], collector types for benefiting from solar energy more, Tiwari et al. [13] and Goyal [14] for determining heat and mass transfer characteristics, Phoungchandang and Woods [15], mathematical models for describing the drying process, have been examined using experimental and numerical ways-drying process. Most of these studies were compared with the experiments performed by drying in open air under natural conditions [16-17].

However, very little information exits in the available literatures regarding the products heat and mass transfer drying characteristics. Boyce [18] studied the convective heat transfer coefficient of a thin layer of barley and developed an equation for the volumetric heat transfer coefficient. O'Callaghan et al. [19] used Boyce's equation in computer simulation of wheat drying. Alanis et al. [20] studied heat transfer in a rock pile but with a lower air flow rate. In their study, particles much larger than grain were used, so they concluded that further studies on the convective heat transfer coefficient in a packed bed of grains are required. Wang et al. [21] measured the convective heat and mass transfer coefficients for crops namely wheat and gram in packed beds. The removal of moisture from the crop was determined under simulated conditions and it was used to develop heat and mass transfer relation using linear as well as multiple regression analysis. The results were recorded for relative humidity, temperature of crop and air and for moisture evaporated. Khandkar and Woods [22] determined the heat transfer coefficient of barley by an experimental method using Schumann's technique. The heat transfer coefficient was found to be a function of air flow rate. They also found that, the values of heat transfer coefficients varied between 43 and $59 \mathrm{~W} / \mathrm{m}^{2} \mathrm{~K}$ depending upon the form of drying model. Goyal and Tiwari [14] also studied heat and mass transfer in product drying systems and reported the values of convective heat transfer coefficient for wheat and gram as 12.68 and $9.62 \mathrm{~W} / \mathrm{m}^{2} .{ }^{\circ} \mathrm{C}$, respectively, by using simple regression technique and 9.67 and 10.85 $\mathrm{W} / \mathrm{m}^{2}{ }^{\circ} \mathrm{C}$, respectively, for the same products while using the multiple regression technique.

Heat transfer coefficients for natural convection, are usually presented as Nusselt number and/or Sherwood number versus Grashof number correlations for the specific geometry. In published literature these could be found for solar heating equipment, Phoungchandang [15] and Pangavhane [23], for large containers, Tanner et al. [24], and also for natural fruit dehydration, and more generally for plate transfer to an infinite environment, Tiwari [13] and Anwar [17]. In the standard form $[\mathrm{Nu}=\mathrm{C}(\mathrm{Gr}$ $\mathrm{Pr})^{\mathrm{n}}$ or $\mathrm{Sh}=\mathrm{C}^{\prime}(\mathrm{Gr} . \mathrm{Sc})^{\mathrm{n}_{1}}$ ] the coefficient is strongly dependent on geometry and drying mode. A group of heat transfer correlations was proposed to predict the heat transfer coefficient inside enclosures used in product purposes such as transportation and storages [25-28]. Anwar and Tiwari [3, 17] determined the convective heat transfer coefficients of six products (green chilies, green peas, white gram, onion, potato and cauliflower) dried under open sun drying conditions with natural convection and indoor open and closed simulated conditions with forced convection mode. They observed that, the values of convective heat transfer coefficient varied from product to product with a range of $3.5-26 \mathrm{~W} / \mathrm{m}^{2}{ }^{\circ} \mathrm{C}$ under open sun drying conditions with the natural convection mode and $1.31-12.80 \mathrm{~W} / \mathrm{m}^{2}{ }^{\circ} \mathrm{C}$ under the forced mode in indoor open simulated conditions and $1.25-10.94 \mathrm{~W} / \mathrm{m}^{2}{ }^{\circ} \mathrm{C}$ under the forced mode in indoor closed simulated conditions for the products studied. Velic et al. [29] investigated the influence of air flow velocities on heat transfer coefficient at convection drying of apple in laboratory conditions. They observed that, the heat transfer coefficient increased with the increase of the air flow, and its range was 21.4 and $44.3 \mathrm{~W} / \mathrm{m}^{2}{ }^{\circ} \mathrm{C}$. Togrul [30] also evaluated the convective heat transfer coefficient 
operating in crop drying in open sun drying conditions and determined that, the values of convective heat transfer coefficient varied with a range of $0.25-3.3 \mathrm{~W} / \mathrm{m}^{2}{ }^{\circ} \mathrm{C}$ for the crops studied.

In this work, four products; namely: apricot, grapes, onion and potato have been dried in a new conical solar dryer to determine the Nusselt and Sherwood numbers considering the size of dryer. Results were also compared with that of the boxtype, collector-mode solar dryers. The proposed correlations for both Nusselt and Sherwood numbers as a function of Grashof numbers were validated with the experimental data. A suitable empirical model is presented to determine the convective heat and mass transfer coefficients as a function of drying time under natural convection mode. The present approach also considers the analogy between heat and mass transfer during the drying process.

\section{MATERIALS AND METHODS}

\subsection{Experimental Set-up}

The solar dryers were designed, fabricated and the experimental tests performed at faculty of Engineering, Shebin El-Kom, Minoufiya University, Egypt. Shebin El- Kom is at an altitude of $30.5^{\circ} \mathrm{N}$. The solar dryers were constructed with materials that were readily available in the local area. The performance of dryers was evaluated at the month of July 2009. The tested solar dryers had an east-west orientation during the experiments. The products; grapes, apricot, onion and potato, used in these experiments were obtained from the public market and were cleaned well from dirt. The fresh samples of onion and potato were cut into thin slices. They were $6 \mathrm{~mm}$ in thickness. Then, all samples were spread on drying trays and placed inside the solar dryers. Each test run started at 7:00 A. M. and continued until 7:00 P. M. The initial weight of samples in each unit was 500 grams. The samples were distributed in the form of a thin layer to receive the same required amount of solar radiation. Three geometers of solar dryers were tested: box-type, solar dryer with collector and conical solar dryer. Four types of conical solar dryers with a ratio of the cone height to dryer diameter of $\mathrm{L} / \mathrm{D}=0.5,1,1.5$ and 2 were investigated.

\subsubsection{Box-Type Solar Dryer}

The solar dryer has the shape of a home cabinet with tilted transparent top. The angle of the slope of the dryer is $30^{\circ}$ according to the latitude of location. Ventilation holes are provided at the bottom and other holes are also provided on the upper surface sides of the dryer. The outlet holes are placed at a higher level of the box. The movement of air through the holes brings a thermo-syphon effect which creates an updraft of heated air with moisture out of the drying chamber. The source of air is under natural flow conditions.

Figure 1-a shows a schematic diagram of the boxtype solar dryer. A transparent cover made of plastic was used. The frame of the box-type dryer is made of wood sheets. An insulated layer of $5 \mathrm{~cm}$ thickness made also of wood was used to reduce the heat loss from the dryer to the ambient. The sides and bottom of the dryer's beds are painted black internally for absorbing solar radiation transmitted through the transparent cover. Seven calibrated Chromel-Alumel thermocouples were used for measuring the products surface, drying air, inlet and outlet temperatures.

\subsubsection{Solar Dryer with Collector}

Figure 1-b shows a schematic diagram of the natural convection solar dryer with collector. The dryer has three main features: the box-type absorber solar air collector, the drying chamber with a drying racks and the chimney. The frame of the absorber was made of wood of $2 \mathrm{~cm}$ thickness. The interior surface of the absorber was painted black to enhance the absorption of solar energy. The effective area of the collector is $150 \times 60 \mathrm{~cm} 2$. The collector area is covered with a transparent plastic sheet of $0.1 \mathrm{~cm}$ thickness. The drying chamber consists of two drying racks, each with an area of $36 \times 28 \mathrm{~cm} 2$ and depth of $10 \mathrm{~cm}$. The racks are made of wooden frame with screen metal used to construct the bottom of drying chamber to allow the free air to flow through the products and out through the chimney which is located at the top of the drying chamber. The drying chamber has a cross section area of $1008 \mathrm{~cm} 2$ and a height of $40 \mathrm{~cm}$. The distance between the inlet and outlet air is $175 \mathrm{~cm}$. The inclination angle of the collector to the horizontal plane is fixed at $30^{\circ}$ to receive the maximum solar radiation during the drying test period.

\subsubsection{Conical Solar Dryer}

Figure 1-c shows the schematic diagram of the conical solar dryer which has a single covered conical collector shape with a bed dryer. The heated air acquired by the transparent cover is made of plastic which transparent the solar radiation and limits the heat loss. The main body of the dryer is made of wooden board with additional insulated layers made also of wood to reduce the heat loss. The sides and bottom of the conical dryers are painted black internally for absorbing solar radiation transmitted through the cover. Air inlet holes are provided at the bottom of the bed dryer and an air exit port of $20 \mathrm{~cm}$ inside diameter is also provided on the top cone section area of the dryer (chimney). Products are spread on trays, having wire mesh at the top bed dryer and exposed to solar radiation, the temperature of products rises resulting in evaporation of moisture. The warm moist air passes through the upper chimney by natural convection, creating a 
partial vacuum and drawing fresh air up through the holes provided at the dryer base. Ambient air enters the dryer through the holes at the bottom, passes through the products spread on the wire mesh which are at a higher temperature due to solar radiation through the transparent cover and escapes with moisture vapors through the upper chimney.

In this work four models of conical solar dryers were designed with height to diameter ratio of $0.5,1$, 1.5 and 2. For all models, the diameter of the dryer is equal to $113 \mathrm{~cm}$. The products used for drying process were apricot, grapes; onion and potato. The same weights of samples were maintained simultaneously for products used inside the dryers. The measurements were performed at the same time for all products. Air enters from the bottom of the dryer through the holes and heated due to the solar radiation. Then, it leaves through the chimney of the cone due to the natural convection mode. The drying chamber contains drying racks with an area of 1962 $\mathrm{cm}^{2}$ and depth of $10 \mathrm{~cm}$.

\subsection{Measurements and Instrumentation}

The measuring instruments used in this work can be divided into weights, temperatures and solar radiation devices. During each test, the products are weighted periodically using an electronic balance of \pm 0.001 gm sensitivity by removing them from the unit for approximately 25 seconds.

Calibrated Chromel-Alumel thermocouples (Type-K) were used to measure the drying air temperatures inside the dryers. The thermocouples were fixed inside the conical dryers at four different positions distributed at equally spacing inside the midline and the average value was considered. The ambient air dry and wet bulb temperatures were measured by mercury thermometers with an accuracy of $\pm 0.5{ }^{\circ} \mathrm{C}$. For each dryer, another two thermocouples were used to measure the air temperature at the inlet and exit of the dryer. Four thermocouples were also used for measuring the surface temperature of the products. Figure 1 illustrates the position of the thermocouples inside the dryers. Eppley pyranometer was used to measure the global and diffuse solar radiation. The sensitivity of the device is $\pm 8.93 \mu \mathrm{v} / \mathrm{Wm}^{-2}$.

\subsection{Experimental Uncertainty}

Errors and uncertainties in the experiments can arise from instrument selection, condition, calibration, environment, observation, reading and test planning. In the drying experiments of the products, the weight and temperatures were measured with appropriate instruments. During the measurements of the parameters, the uncertainties that occurred are presented in Table 1.

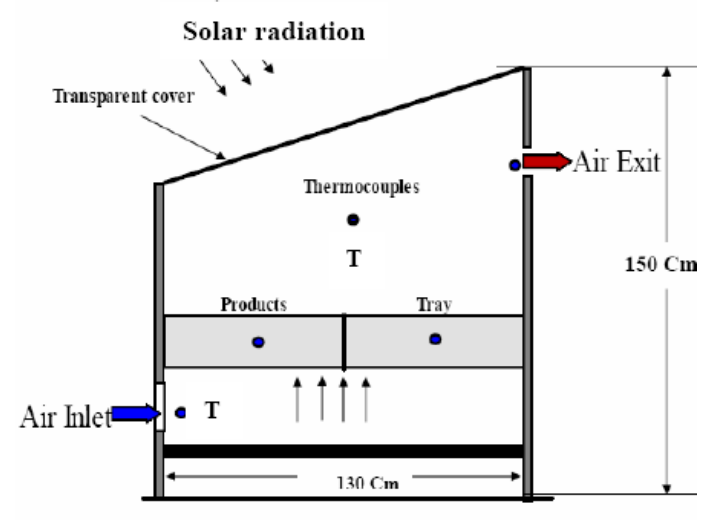

(a)

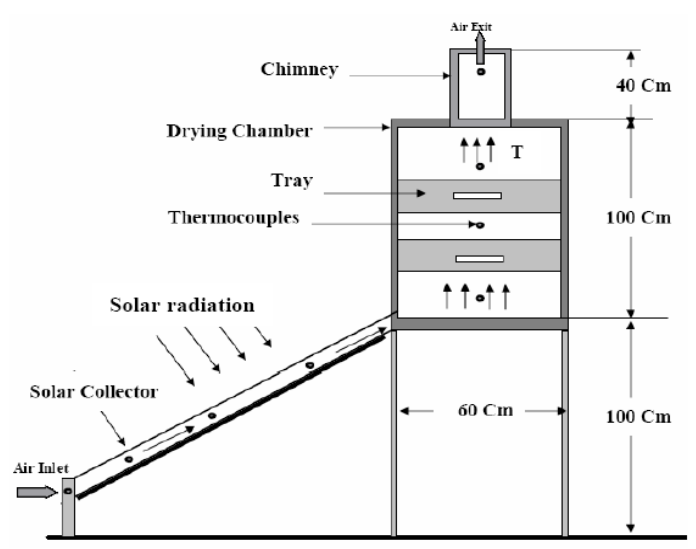

(b)

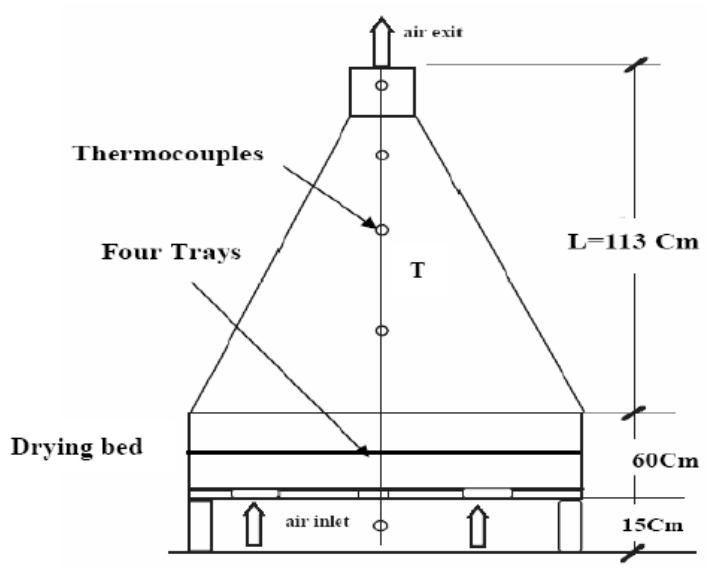

(c)

Fig. 1 Position of the thermocouples inside the dryers

Table 1, Uncertainties of the measured parameters during drying process

\begin{tabular}{|c|c|}
\hline Parameter & $\begin{array}{l}\text { Uncertai } \\
\text { nty }\end{array}$ \\
\hline Electronic Balance. & $\pm 0.001 \mathrm{gm}$ \\
\hline Mercury Thermometer. & $\pm 0.5^{\circ} \mathrm{C}$ \\
\hline The Eppley Pyranometer. & $\pm 8.93 \mu \mathrm{N} / \mathrm{Wm}$ \\
\hline $\begin{array}{lll}\text { Chromel } & - & \text { Alumel } \\
\text { thermocouples. } & & \\
\end{array}$ & $\pm 0.01 \mathrm{mv}$ \\
\hline
\end{tabular}




\subsection{Thermal Model}

\subsubsection{Determination of convective heat transfer coefficient}

Convective heat transfer occurs between a moving fluid and a solid surface. In this work, the convective heat transfer is investigated by a natural convection flow. The convective heat transfer coefficient (hc) can be determined using the expression for Nusselt, Grashof, and Prandtl numbers as follows $[3,13,17]$ :

$$
N u=\frac{h_{c} \cdot X}{K_{v}}=C(G r . P r)^{n}
$$

Where $\mathrm{C}$ and $\mathrm{n}$ are empirical constants, and:

$$
\begin{aligned}
G r & =g \beta X^{3} \rho_{V}{ }^{2} \Delta T / \mu_{V}{ }^{2} \\
\operatorname{Pr} & =\mu_{v} \cdot C_{v} / K_{v}
\end{aligned}
$$

The rate of heat utilized for moisture evaporation is given as [13]:

$$
Q_{e}=0.016 h_{c}\left[P\left(T_{s}\right)-\gamma P\left(T_{e}\right)\right]
$$

Where:

$$
h_{c}=K_{v} C(G r \cdot \operatorname{Pr})^{n} / X
$$

$\mathrm{P}$ (Ts) is the saturation pressure of water at product surface temperature and $\mathrm{P}(\mathrm{Te})$ is the partial pressure of water vapor at dryer exit.

By substituting (hc) from Eqn. (5) into Eqn. (4), the heat evaporation becomes:

$$
Q_{e}=0.016\left(K_{v} / X\right) C(G r \cdot \operatorname{Pr})^{n}\left[P\left(T_{s}\right)-\gamma \cdot P\left(T_{e}\right)\right]
$$

The moisture evaporated is determined by dividing Eqn. (6) by the latent heat of vaporization $\left(\mathrm{h}_{\mathrm{fg}}\right)$ and multiplying the area of product drying tray (A) and time interval $(\mathrm{t})$ :

$$
\begin{aligned}
& \therefore m_{e v}=Q_{e} A t / h_{f g} \\
& \therefore m_{e v}=0.016\left(K_{v} / X . h_{f g}\right) C(G r \cdot \operatorname{Pr})^{n}\left[P\left(T_{s}\right)-\gamma \cdot P\left(T_{e}\right)\right] . A . t \quad(7) \\
& \text { Putting: } \\
Z & =0.016\left(K_{v} / X . h_{f g}\right)\left[P\left(T_{s}\right)-\gamma \cdot P\left(T_{e}\right)\right] . A t
\end{aligned}
$$

Equation (7) becomes:

$$
\left(m_{e v} / Z\right)=C(G r \cdot \operatorname{Pr})^{n}=N u=h_{c} \cdot X / K_{v}
$$

Taking the logarithm of both sides:

$$
\ln \left(m_{e v} / Z\right)=\ln C+n \ln (G r . \operatorname{Pr})
$$

Equation (8) is linear relation between $\ln (\mathrm{Z})$ and $\ln (\mathrm{Gr}$. Pr) with a slope of $\mathrm{n}$ and a constant of $\ln \mathrm{c}$ : Where $\mathrm{y}=\ln \left[\mathrm{m}_{\mathrm{ev}} / \mathrm{Z}\right]$ and $\mathrm{x}=\ln [\mathrm{Gr} . \mathrm{Pr}]$ With $\mathrm{m}=\mathrm{n}$, and $\mathrm{c}=\ln \mathrm{C}$ gives $\mathrm{C}=\mathrm{e}^{\mathrm{c}}$

By using the experimental data for $\mathrm{T}_{\mathrm{s}}, \mathrm{T}_{\mathrm{e}}, \gamma$ and $\mathrm{m}_{\mathrm{ev}}$, the values of $\mathrm{y}$ and $\mathrm{x}$ can be evaluated for different time interval and then the constant $\mathrm{C}$ and exponent $\mathrm{n}$ can be obtained from above equations for the natural mode of drying and the theoretical values of Nusselt numbers may be determined from Eqn. (1). The results for $\mathrm{C}$ and $\mathrm{n}$ for each drying unit are given in Table 3.

\subsubsection{Determination of convective mass transfer coefficient}

The convective mass transfer coefficients can be determined using the expression for Sherwood (Sh), Grashof (Gr) and Schmidt (Sc) numbers as follows [31]:

$$
\begin{aligned}
& S h=\frac{h_{m} \cdot X}{D}=C^{\prime} .(G r \cdot S c)^{n^{\prime}} \\
& \text { Where: } C^{\prime} \text { and n' are empirical con }
\end{aligned}
$$

$$
\mathrm{Sc}=\mu \mathrm{v} /(\rho \mathrm{v} . \mathrm{D})
$$

The diffusion coefficients, $\mathrm{D}$, is given by [31]:

$$
D=1.87 \times 10^{-10} \cdot \frac{T}{P}^{2.072}
$$

Where $\mathrm{P}$ is the total pressure in atm and $\mathrm{T}$ is the humid air temperature in $\mathrm{K}$.

The Chilton-Colburn analogy between heat and mass transfer is used to evaluate the mass transfer coefficient as follow [31]:

$$
\frac{h_{c}}{h_{m}}=\rho \cdot C_{p} \cdot L e^{2 / 3}
$$

Where Le is the Lewis number, $\mathrm{Le}=\alpha / \mathrm{D}$.

By substituting (hm) from Eqn. (13) into Eqn. (10), the moisture evaporated, the Sherwood number and convective mass transfer coefficient become:

$$
\begin{gathered}
m_{e v}=0.016 \frac{D \cdot A t}{X \cdot h_{f g}} C^{\prime}(G r S S c)^{n^{\prime}} \rho C_{p} L e^{2 / 3}\left[P\left(T_{s}\right)-\gamma P\left(T_{e}\right)\right] \\
\left(m_{e v} / Z^{\prime}\right)=C^{\prime}(G r S c)^{n^{\prime}}=S h=h_{m} X / D \\
\text { Where: } \\
Z^{\prime}=0.016 \frac{D \cdot A . t}{X . h_{f g}} \rho C_{p} L e^{2 / 3}\left[P\left(T_{s}\right)-\gamma P\left(T_{e}\right)\right]
\end{gathered}
$$

The ratio between the parameters $\mathrm{Z}$ and $\mathrm{Z}^{\prime}$ is given by:

$$
Z^{\prime}=Z \frac{D}{K_{v}} \rho \cdot C_{p} L e^{2 / 3}
$$

The constants $C^{\prime}$ and $n^{\prime}$ can be determined in a manner similar to that of Eqn. (1) and the theoretical values of Sherwood numbers may be obtained from Eqn. (10). The results for the values of $C^{\prime}$ and $n^{\prime}$ for each drying unit are also given in Table 4.

\subsubsection{Analogy between heat and mass transfer}

Based on the analogy between heat and mass Transfer, Eqn. (8) and (15) can be rewrite in the form of Eqn. (18) as follows:

$$
\left(\frac{N u}{G r \cdot \operatorname{Pr}}\right)=a \cdot\left(\frac{S h}{G r \cdot S c}\right)^{b}
$$


Where $\mathrm{a}$ and $\mathrm{b}$ are constants, which may be obtained with the aid of the experimental data of dimensionless parameters for different tested solar dryers.

For unsteady operation conditions, the values of drying air and products surface temperatures vary significantly because of the variations in the climatic conditions and consequently $m_{e v}, \mathrm{Nu}, \mathrm{Sh}$ and the analogy between heat and mass transfer are also vary.

\subsubsection{Determination of physical properties of humid air}

The different physical properties of humid air, i.e. density $(\rho v)$, thermal conductivity $(\mathrm{Kv})$, specific heat $(\mathrm{Cv})$, viscosity $(\mu \mathrm{v})$, and latent heat of vaporization $\left(\mathrm{h}_{\mathrm{fg}}\right)$ were used in the computation of Nusselt, Prandtl, Grashof, Sherwood and Schmidt numbers. The following polynomial expressions were used for obtaining the physical properties of humid air [14, 29, 33]:

$$
\begin{aligned}
& \rho_{v}=\frac{353.44}{\left(T_{i}+273.15\right)} \\
& K_{v}=0.0244+0.6773 \times 10^{-4} T_{i} \\
& C_{v}=999.2+0.1434 T_{i}+1.101 \times 10^{-4} T_{i}^{2}-6.7581 \times 10^{-8} T_{i}^{3} \\
& \mu_{v}=1.718 \times 10^{-5}+4.620 \times 10^{-8} T_{i} \\
& \text { where, } T_{i}=\left(T_{s}+T_{e}\right) / 2 \\
& P(T)=\exp \left[25.317-\frac{5144}{(T+273.15)}\right]
\end{aligned}
$$

Where, Ti is taken as the average of the drying air and product surface temperatures. The values of the constants $\mathrm{C}, \mathrm{C}^{\prime}, \mathrm{n}, \mathrm{n}$, $\mathrm{a}$ and $\mathrm{b}$ have been determined by linear regression analysis by using the measured data of the moisture evaporated as well as the drying air and products surface temperatures during an interval period of 30 minutes. The convective heat and mass transfer coefficients $\left(\mathrm{h}_{\mathrm{c}}, \mathrm{h}_{\mathrm{m}}\right)$ were determined by using equations (5) and (13), represented with the aid of the Nusselt number and the Chilton-Colburn analogy, respectively, while the theoretical values were determined using equations (8) and (15), respectively. The coefficient of correlation $\mathrm{R}^{2}$ was computed for the experimental data of hc and hm for suitability of the model.

\section{RESULTS AND DISCUSSIONS}

\subsection{Convective Heat Transfer}

The daytime variation of the ambient and wet bulb temperatures, solar radiation and relative humidity of air are shown in Fig. 2. From this figure, it is observed that, the rise in the air temperatures due to the generated air flow rates inside the dryers were sufficient for the purpose of products drying, particularly in the dryer with $\mathrm{L} / \mathrm{D}=1$. The range of the ambient air temperatures and relative humidity were changed from $23{ }^{\circ} \mathrm{C}$ to $37^{\circ} \mathrm{C}$ and from $30 \%$ to $55 \%$, respectively, during the drying period. Table 2 gives the temperature difference between the mean drying air temperature inside the dryer and the dry-bulb temperature $\Delta T^{\prime}$ for all cases. The maximum difference in the air temperature rise of $24{ }^{\circ} \mathrm{C}$ was recorded for the conical solar dryer with $\mathrm{L} / \mathrm{D}=1$, as shown in Table 2 . The average relative humidity during the drying period of three days was $43 \%$. The relative humidity variation with drying time is also presented in Fig. 2.

Convective heat and mass transfer coefficients are important parameters, which are a measure of the resistance to heat and mass transfer between the product surface and the air flowing over that surface. Figure 3 shows the Nusselt number $(\mathrm{Nu})$ as a function of the product of the Grashof and Prandtl numbers (Gr.Pr); Rayleigh number (Ra), for the products tested in different solar dryers. For all products, the $\mathrm{Nu}$ values increases with increasing the Ra number. The rate of increase for all dryers is nearly constant except for the dryer with $\mathrm{L} / \mathrm{D}=1$, which gives the highest rate of increase. The variation in $\mathrm{Nu}$ values may be due to the difference of porosity, moisture content, thermo-physical properties, shape and size of the products to be dried. It is clear also that, the $\mathrm{Nu}$ of the potato and onion slices were closed to each other. Table 2 gives the values of heat transfer coefficients as well as the Nusselt numbers for different dried products in the tested units. The best values of $\mathrm{Nu}$ ranged between 178 and 448 were obtained for conical solar dryer with $\mathrm{L} / \mathrm{D}=1$ compared with the box and the other types of tested solar units, as shown in Table 2. The minimum values of $\mathrm{Nu}$ were obtained for grapes (143-186) followed by apricot (178-212) and onion (221-443), while the best $\mathrm{Nu}$ values were obtained for potato (284-448) with conical solar dryer of $\mathrm{L} / \mathrm{D}=1$. This shows the importance of product selection for drying while designing an effective dryer. The drying mode also affects the convective heat transfer under natural convection for products drying. Figure 4- a, b, c and d represents the variation of the Nusselt number versus the product of the Grashof and Prandtl numbers (Gr.Pr) for apricot, grapes, onion and potato for different solar dryers. 


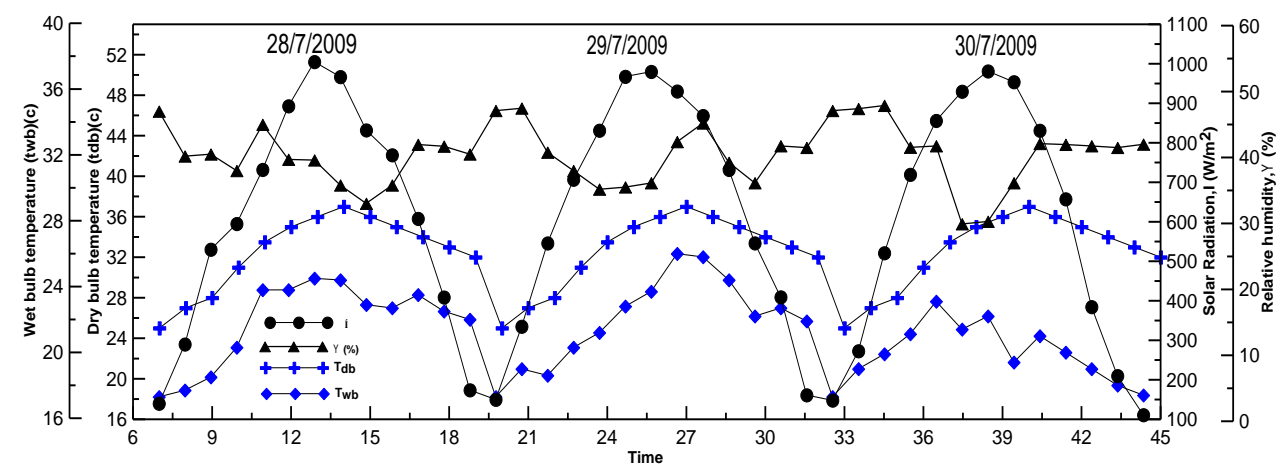

Fig.2 Hourly variations of solar radiation, relative humidity, dry and wet bulb temperatures during the three drying days

The Rayleigh number ( $\mathrm{Ra}$ ) is ranged between $0.3 \times 106$ and $9.5 \times 108$ depending on the achieved drying mode. It is clear that, the maximum values of the $\mathrm{Nu}$ are obtained for the conical solar dryer with $\mathrm{L} / \mathrm{D}=1$, while the minimum values is for the dryer with $\mathrm{L} / \mathrm{D}=2$. This also shows that he is lower in the case of conical dryer with $\mathrm{L} / \mathrm{D}=1.5$ and 2 relative to $\mathrm{L} / \mathrm{D}=1$. This was mainly due to the increase in the relative humidity inside the conical dryers with $\mathrm{L} / \mathrm{D}=1.5$ and 2 , thus the rate of moisture removal decrease. Since $\mathrm{m}_{\mathrm{ev}}$ depends on the partial pressure difference between the product surface and the surrounding humid air, (Eqn. (7)), higher the relative humidity, the lower is the partial pressure difference, resulting in lowering the $\mathrm{m}_{\mathrm{ev}}$. Table 3 presents the obtained values of $\mathrm{C}, \mathrm{n}$ and $\mathrm{R} 2$ for all the products under study in the tested solar units. It could be seen from this table that, the changes in coefficients $\mathrm{C}$ and $\mathrm{n}$ are varies for the different dryers and the different products.

Figure 5 shows the effect of the dryer height to diameter ratio (L/D) on the values of $\mathrm{Nu}$ for tested products at different drying times. From these figures, it is clearly indicated that, $\mathrm{Nu}$ is very high in the beginning of drying. This is could be due to the high initial moisture content of the product. Thus, the rate of moisture evaporation $\left(\mathrm{m}_{\mathrm{ev}}\right)$ is very high in the beginning, and the products surface behaves like a wetted surface. This proves that, $h_{c}$ is a strong function of $\mathrm{m}_{\mathrm{ev}}$. It can be also noticed that, the conical dryer with $\mathrm{L} / \mathrm{D}=1$ gives the highest values of $\mathrm{Nu}$ compared with the other types of solar dryers. The $\mathrm{Nu}$ increases with increasing $\mathrm{L} / \mathrm{D}$ up to $\mathrm{L} / \mathrm{D}=1$, and then starts to decrease and reaches to minimum values at $\mathrm{L} / \mathrm{D}>1$. A reason of this behavior may be due to the change of both the heat of vaporization and the rate of heat transfer supplied from the surroundings humid air inside the dryer, which may be equal at $\mathrm{L} / \mathrm{D}=1$. However, at $\mathrm{L} / \mathrm{D}<1$, the heat of vaporization increases, while the rate of heat transfer supplied from the surrounding humid air dominates and the $\mathrm{Nu}$ decreases, at $\mathrm{L} / \mathrm{D}>1$.

\subsection{Convective Mass Transfer}

Figure 6 represents the relation between the Sherwood number (Sh) and the product of the Grashof and Schmidt numbers (Gr. Sc) for different modes of drying with all products. The values of Sherwood number increase with increasing the product of the Grashof and Schmitt numbers. The rate of increase is nearly constant for all solar dryers except for the dryer of $L / D=1$, which gives the highest rate of increase compared with the box-type solar dyer and the other tested units, as shown in Table 2. It is also noticed that, the potato gives the best values of Sh ranged between 253 and 384, followed by onion, 210-420 and apricot, 142-208, while grapes gives the lower values of Sh that ranged between 139 and 193 . Table 4 presents the values of $\mathrm{C}^{\prime}, \mathrm{n}^{\prime}$ and R2 for different products dried in the tested solar units.

Figure 7 represents the relation between the Sherwood number (Sh) and the product of the Grashof and Schmidt numbers (Gr. Sc) for a specified product in all tested solar dryers. It is clear that, the maximum values of the Sh were obtained for the conical solar dryer with $\mathrm{L} / \mathrm{D}=1$, while the minimum values were obtained for the solar dryer with $\mathrm{L} / \mathrm{D}=2$. Again, as can be seen from this figure, the Sh of the onion and potato slices were near each other. The maximum values were obtained for the onion slices, while the value of Sh for grapes was found to be the lowest.

Figure 8 represent the effect of the height to dryer diameter ratio (L/D) on the values of Sh for apricot, grapes, onion and potato at different drying times. From these figures, It can be noticed that, the behaviors of Sh with respect to drying time for tested products were similar to that of $\mathrm{Nu}$ in the beginning of drying process, which also confirms that, $\mathrm{h}_{\mathrm{m}}$ is also a strong function of $\mathrm{m}_{\mathrm{ev}}$. It is clearly indicated that, the conical solar dryer with $\mathrm{L} / \mathrm{D}=1$ gives the highest values of Sherwood number compared with that of the other tested solar dryers. The Sherwood number increases with increasing $\mathrm{L} / \mathrm{D}$ ratio up to 
$\mathrm{L} / \mathrm{D}=1$, and then starts to decrease and reaches to minimum values at $\mathrm{L} / \mathrm{D}=2$. A reason of this may be owing to the change of both moisture losses and moisture sources with changing L/D ratio, which they may be equal at $\mathrm{L} / \mathrm{D}=1$. However, at $\mathrm{L} / \mathrm{D}<1$, the moisture sources increase while, the moisture losses dominate and the mass transfer decreases at $\mathrm{L} / \mathrm{D}>1$.

\subsection{The Analogy between Heat and Mass Transfer}

Some authors used the Chilton-Colburn analogy to determine the mass transfer coefficient in terms of the heat transfer coefficient [6,7]. Chen et al [32] found that, the heat to mass transfer coefficient ratio, obtained based on a heat balance equation for a thin water evaporation layer, is different from that derived from the conventional Chilton-Colburn analogy. In this work, however, the analogy between heat and mass transfer is achieved by determining the ratio of $\mathrm{Nu} / \mathrm{Sh}$ based on the experimental data with the aid of the Chilton-Colburn analogy and also by drawing the relation between (Nu/Gr.Pr) as a function of (Sh/Gr.Sc), as shown in Fig. 9. Table 2 presents the ratio of $\mathrm{Nu} / \mathrm{Sh}$ during drying for all tested drying units. It can be observed from Table 2 that, the values of the ratio $\mathrm{Nu} / \mathrm{Sh}$ ranged between 1.02 and 1.25 and between 1.09 and 1.20 in conical dryer with $\mathrm{L} / \mathrm{D}=1$ and box-type dryer, respectively, for apricot. The increase of the percent variation ranged between $2 \%$ and $25 \%$ and between $9 \%$ and $20 \%$ in conical solar dryer with $\mathrm{L} / \mathrm{D}=1$ and box-type dryer, respectively, when the values of apricot is compared with the other products. However, the difference between the minimum and maximum values of the ratio $\mathrm{Nu} / \mathrm{Sh}$ depends on the drying mode as well as the dried products, as shown from Table 2 .

For drawing the relation between (Nu/Gr.Pr) versus (Sh/Gr.Sc), all the experimental data are treated in the form of Eqn. (18) in order to obtain a group of empirical correlations for describing the analogy between heat and mass transfer for all solar dryers. Figure 9 indicates that, there is a linear relationship between heat and mass transfer coefficients for all tested dryers and products. The proposed empirical correlations for describing the analogy between heat and mass transfer for different solar dryers are given in Table 5. This table also presents the values of $\mathrm{R} 2$ as well as the range of parameters (Gr. Pr) and (Gr. Sc). The proposed empirical correlations could be used for the prediction of the average mass transfer coefficients for natural convection drying systems with a good accuracy.

\subsection{Comparison of the Calculated Results and the Experimental Measurements}

Figure 10 indicates a sample of results for comparison of the predicted and experimental measurements of the Nusselt and Sherwood numbers as well as the parameter $(\mathrm{Nu} / \mathrm{Gr}$.Pr) by established model in solar conical dryer with $L / D=1$. From this figure, it is clear that, the present model provides a good agreement between the predicted results and the experimental values of $(\mathrm{Nu}),(\mathrm{Sh})$ and $(\mathrm{Nu} / \mathrm{Gr} . \mathrm{Pr})$ and the predicted data bounded around the straight line. This showed the suitable of the model in describing solar drying behavior of dried products.

\section{CONCLUSIONS}

Convective heat and mass transfer coefficients as well as the Nusselt and Sherwood numbers have been determined for four different products (apricot, grapes, onion and potato) to obtain the values of the constants $\mathrm{C}, \mathrm{C}^{\prime}, \mathrm{n}, \mathrm{n}^{\prime}$, a, and $\mathrm{b}$ under natural convective mode by using the experimental products surface temperatures, relative humidity, drying air temperatures and the moisture evaporated data for a conical solar dryers. A comparison between the convective heat and mass transfer of the proposed new conical-type solar dryers with a height to diameter ratios of $0.5,1,1.5$ and 2 as well as both of the box-type and the solar dryer with collector is considered. The solar conical dryer with a height to diameter ratio of unity was found to be more efficient than that of the other tested drying units. The values of the Nusselt and Sherwood numbers depend on the type of product used as well as the mode of drying. These values were found to be varied from 178 to 448 and from 139 to 420 for Nusselt numbers and Sherwood numbers, respectively, for conical solar dryer with $\mathrm{L} / \mathrm{D}=1$ compared with the box and other types of tested units, as shown in Table 2. The values of the constants, C, $\mathrm{C}^{\prime}, \mathrm{n}$, and n' were determined by linear regression analysis from experimental data obtained for products and recorded in Tables 3 and 4 . The heat and mass transfer coefficients predicted by the proposed equations were in a good agreement with the experimentally obtained values. The change in the heat and mass transfer coefficients expressed in terms of the Nusselt and Sherwood numbers varied significantly due to the difference in porosity, initial moisture content, shape, size of products and thermophysical properties.

The analogy between the heat and mass transfer showed a linear relationship between the dimensionless parameters (Nu/Gr.Pr) and (Sh/Gr.Sc). General empirical correlations for describing the analogy between the heat and mass transfer for all tested solar dryers were also introduced in Table 5. The importance of these empirical correlations is attributed to the possibility of determination the mass transfer coefficients with the aid of the heat transfer coefficients with a sufficient accuracy. 


\section{NOMENCLATURE}

\begin{tabular}{|c|c|}
\hline \multicolumn{2}{|c|}{ A $\quad$ Area of tray, $\mathrm{m}^{2}$. } \\
\hline \multicolumn{2}{|c|}{$\mathrm{a}, \mathrm{b}, \mathrm{C}, \mathrm{n}, \mathrm{C}^{\prime}, \mathrm{n}^{\prime} \quad$ Constants. } \\
\hline $\mathrm{C}_{\mathrm{v}}$ & specific heat of humid air, $\mathrm{J} / \mathrm{kg}{ }^{\circ} \mathrm{C}$. \\
\hline $\mathrm{D}$ & Mass diffusivity, $\mathrm{m}^{2} / \mathrm{s}$. \\
\hline $\mathrm{g}$ & Acceleration due to gravity, $\mathrm{m} / \mathrm{s}^{2}$. \\
\hline \multicolumn{2}{|c|}{$\mathrm{h}_{\mathrm{c}}$ Convective heat transfer coefficient, $\mathrm{W} / \mathrm{m}^{2}{ }^{\circ} \mathrm{C}$. } \\
\hline $\mathrm{h}_{\mathrm{m}}$ & Mass transfer coefficient, $\mathrm{m} / \mathrm{s}$. \\
\hline $\mathrm{h}_{\mathrm{fg}}$ & Latent heat of vaporization, $\mathrm{J} / \mathrm{kg}$. \\
\hline I & Solar radiation, $\mathrm{W} / \mathrm{m}^{2}$. \\
\hline $\mathrm{K}_{\mathrm{v}}$ & Thermal conductivity of humid air, $\mathrm{W} / \mathrm{m}{ }^{\circ} \mathrm{C}$. \\
\hline $\mathrm{L}$ & Cone height, $\mathrm{m}$. \\
\hline $\mathrm{m}_{\mathrm{ev}}$ & Moisture evaporated, kg. \\
\hline $\mathrm{P}$ & Vapor pressure, $\mathrm{Pa}$. \\
\hline \multicolumn{2}{|c|}{$\mathrm{J} / \mathrm{m}^{2} . \mathrm{s}$} \\
\hline $\mathrm{R}$ & Correlation coefficient. \\
\hline $\mathrm{T}$ & Temperature, ${ }^{\circ} \mathrm{C}$. \\
\hline $\mathrm{T}_{\mathrm{db}}$ & Dry-bulb temperature, ${ }^{\circ} \mathrm{C}$. \\
\hline $\mathrm{T}_{\mathrm{wb}}$ & Wet-bulb temperature, ${ }^{\circ} \mathrm{C}$. \\
\hline $\mathrm{T}_{\mathrm{s}}$ & Product surface temperature, ${ }^{\circ} \mathrm{C}$. \\
\hline $\mathrm{T}_{\mathrm{e}}$ & Exit air temperature, ${ }^{\circ} \mathrm{C}$. \\
\hline $\begin{array}{l}\mathrm{T}_{\mathrm{i}} \\
\text { air, }{ }^{\circ} \mathrm{C} \text {. }\end{array}$ & Average temperature of product and humid \\
\hline
\end{tabular}

$\Delta \mathrm{T} \quad$ Temperature difference between product surface temperature and mean air temperature inside dryer, ${ }^{\circ} \mathrm{C}$.

$\mathrm{t}$ Time, $\mathrm{s}$.

X Characteristic length, $\mathrm{m}$.

\section{Z, Z' Parameters.}

\section{Greek symbols}

$\alpha$ Thermal diffusivity of humid air, $\mathrm{m}^{2} / \mathrm{s}$.

$\beta \quad$ Volumetric thermal expansion coefficient, $\mathrm{K}^{-1}$.

$\gamma \quad$ Relative humidity.

$\mu_{\mathrm{v}} \quad$ Dynamic viscosity, kg. m/s.

$\rho_{\mathrm{v}} \quad$ Density of humid air, $\mathrm{kg} / \mathrm{m}^{3}$.

\section{Dimensionless Groups}

Pr Prandtl number $=\mu_{\mathrm{v}} \cdot \mathrm{C}_{\mathrm{p}} / \mathrm{K}_{\mathrm{v}}$

Gr Grashof number $=g \beta X^{3} \rho_{V}{ }^{2} \Delta T / \mu_{V}{ }^{2}$

Le Lewis number $=\alpha / \mathrm{D}$

$\mathrm{Nu} \quad$ Nusselt number $=\mathrm{h}_{\mathrm{c}} . \mathrm{X} / \mathrm{K}_{\mathrm{v}}$

Ra Rayleigh number $=$ Gr. Pr

Sh Sherwood number $=h_{m}$. X/ D

Sc $\quad$ Schmidt number $=\mu_{v} /\left(\rho_{\mathrm{v}}\right.$. D $)$

\section{REFERENCES}

[1] Lyes Bennamoun and Azeddine Belhamri, (2008), "Mathematical Description of Heat and Mass Transfer during Deep Bed Drying: Effect of Product Shrinkage on Bed Porosity", Applied Thermal Engineering, Vol. 28, PP. 2236-2244.

[2] Kreider J. F. and Kreith F., (1981), "Solar Energy Hand Book", McGraw-hill Book Company, New York, Vol. 18, PP. 1-28.

[3] Anwar S. I. and Tiwari G. N., (2001), "Convective Heat Transfer Coefficient of Crops in Forced Convection Drying - An Experimental Study", Energy Conversion and Management, Vol. 42, PP. 1687-1698.

[4] Ireneusz Białobrzewski, (2007), "Determination of the mass transfer coefficient during hot-airdrying of celery root", Journal of Food Engineering 78 PP. 1388-1396.

[5] Dilip Jain, (2006), "Determination of Convective Heat and Mass Transfer Coefficients for Solar Drying of Fish", Biosystems Engineering, 94 (3), PP. 429-435

[6] Ciesielczyk W., (1996), "Analogy of heat and mass transfer during constant rate period in fluidized bed drying," Drying Technology, 14 (2), PP. 217-230.

[7] Inazu T., Iwasaki K. and Furuta T., (2002), "Effect of temperature and relative humidity on drying kinetics of fresh Japanese noodle (Udon)", Lebensmittel-Wissenschaft undTechnologie, 35, PP. 649-655.

[8] Doymaz İ., (2005), "Drying kinetics of black grapes treated with different solutions", Journal of Food Engineering 71, PP. 403-407.

[9] Dinçer I., and Hussain M. M., (2004), "Development of a new biot number and a lag factor correlation for drying applications", International Journal of Heat and Mass Transfer, 47, PP. 653-658.

[10] Mabrouk S. B., Khiari B. and Sassi M., (2006), "Modelling of heat and mass transfer in a tunnel dryer", Applied Thermal Engineering, 26, PP. 2110-2118.

[11] İsmail O., (2005), "Investigation the effect of potasium carbonate solutions on drying of sultana grapes", Journal of Engineering and Natural Sciences, 1, PP. 108-114.

[12] Othman M. Y. H. Sopian K., Yatim B. and Daud W. R. W. (2006), "Development of advanced solar assisted drying systems", Renewable Energy, 31, PP. 703-709.

[13] Tiwari G. N, Sanjeev Kumar and Prakash O. M., (2004), "Evaluation of Convective Mass Transfer Coefficient During Drying of Jaggery", 
Journal of Food Engineering, Vol. 63, PP. 219227.

[14] Goyal, R. K. and Tiwari G. N., (1998), "Heat and Mass Transfer Relations for Crop Drying", Drying Technology. Vol. 16, PP. 1741-1754.

[15] Phoungchandang S. and Woods J., (2000), "Solar drying bananas: mathematical model, laboratory simulation, and field data compared", Journal of Food Science, 65, (6), PP. 990-996.

[16] Gülşah Çakmak and Cengiz Yıldız, (2009) 'Design of a new solar dryer system with swirling flow for drying seeded grape", International Communications in Heat and Mass Transfer, 36, PP. 984-990.

[17] Anwar S. L. and Tiwari G. N., (2001),"Evaluation of Convective Heat Transfer Coefficient in Crop Drying under open Sun Drying", Energy Conversion and Management, Vol. 42, PP. 627-637.

[18] Boyce D. S., J. Agric. Engng. Res., (1966), Vol.. 4, PP. 255.

[19] O'Callaghan J. R., Menzie D. J. and Baily P. H., (1971), J. Agric. Engng. Res, Vol. 3, PP. 223.

[20] Alanis E., Saravia L. and Rovetta L., (1977), Solar Energy, Vol. 19, PP. 571.

[21] Wang G. Y., Rumsey T. R. and Singh R. P., (1979), "Convective heat transfer in packed bed of rice", ASAE Paper No: 79-3040.

[22] Khandkar MHK and Woods J. L., AMA, (1987), Vol. 4, PP. 39.

[23] Pangavhane R., Sawhney R. and Sarsavadia P., (2002), "Design, development and performance testing of a new natural convection solar dryer", Energy, 27, (6), PP. 579-590.

[24] Tanner D., Cleland A. and Opara L., (2002), "A generalized mathematical modeling methodology for the design of horticultural food packages exposed to refrigerated conditions. Part 2", Heat transfer modeling, International Journal of Refrigeration, 25, (1), PP. 43-53.

[25] Acevedo C., Sanchez E. and Young M. E., (2007), "Heat and mass transfer coefficients for natural convection in fruit Packages", Journal of Food Engineering, 80, PP. 655-661.

[26] Anil Kumar and Tiwari G. N., (2006), "Effect of Shape and Size on Convective Mass Transfer Coefficient during Greenhouse Drying (GHD) of Jaggery", Journal of Food Engineering, Vol. 73, PP. 121-134.

[27] Kavak Akpinar E., (2005), "Evaluation of Convective Heat Transfer Coefficient of Various Crops in Cyclone Type Dryer", Energy Conversion and Management, Vol. 46, PP. 2439-2454.
[28] Akpinar E. K., Midilli A. and Bicer Y., (2003), "Experimental Investigation of Drying Behavior and Conditions of Pumpkin Slices via Cyclone Type Dryer", J. Sci. Food Agric., Vol. 83, PP. 1480-1489.

[29] Velic D., Planinic M., Tomas S. and Bilic M., (2004), "Influence of Airflow Velocity on Kinetics of Convection Apple Drying", J. Food Eng., Vol. 64, PP. 97-102.

[30] Togrul I. T., (2003), "Determination of convective heat transfer coefficients of various crops under open sun drying conditions", Int. Commun. Heat Mass Transfer, 30, (2), PP. 285294.

[31] Yunus A. Cengel, "Heat Transfer: A Practical Approach", (1998), McGraw-Hill, New York, PP. 623-696.

[32] Chen X. D., Lin S. X. Q. and Chen G., (2002), "On the ratio of heat to mass transfer coefficient for water evaporation and its impact upon drying modeling", International Journal of Heat and Mass Transfer, 45, PP. 4369-4372.

[33] Akpinar E. K., Midilli A. and Bicer Y., (2003), "Mathematical Modeling and Experimental Study on Drying of Apple Slices in a Convective Cyclone Dryer", J. Food Process Eng., Vol. 26, PP. 515-541 
Sh. Shams El-Din, M. Habib, A. El-Hanafy, Kh. Ramzy, "Evaluation of Convective Heat and ..."

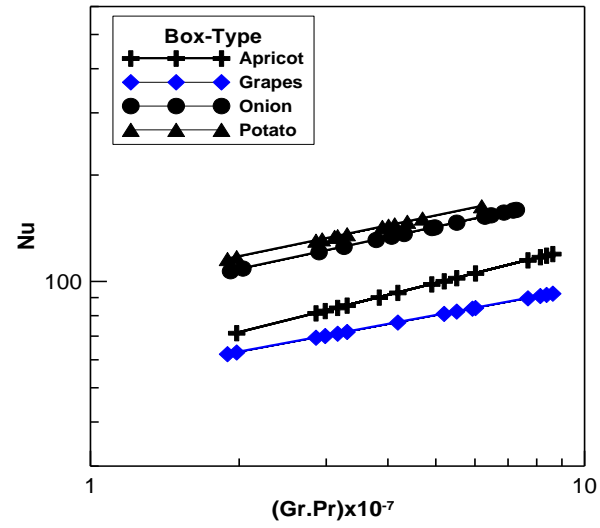

(a)

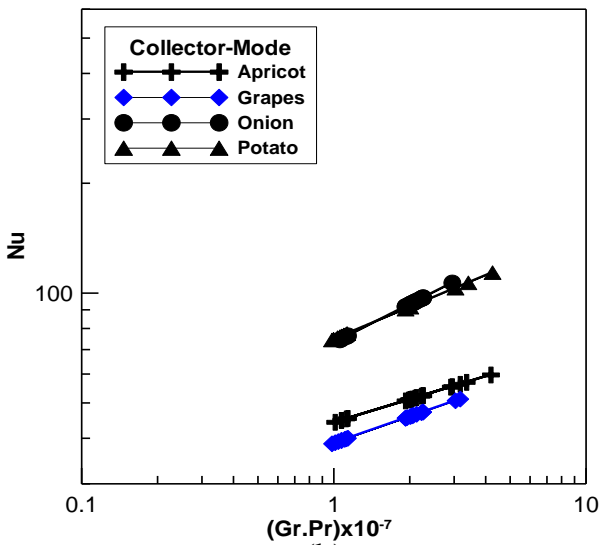

(b)

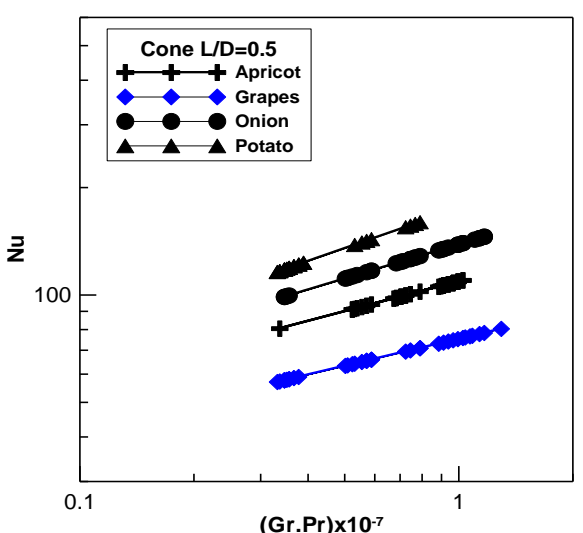

(c)

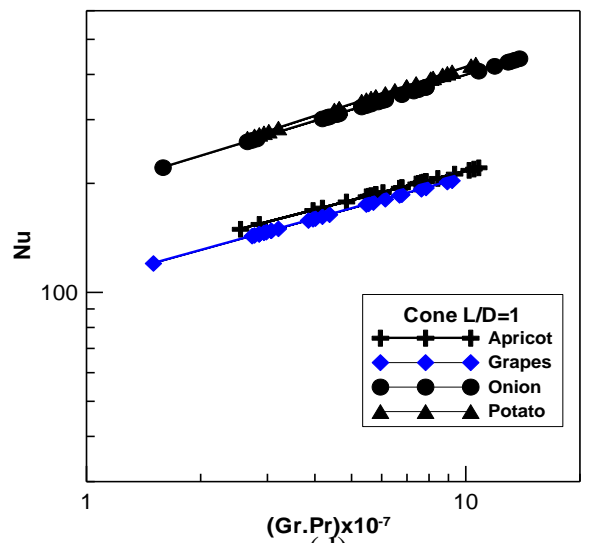

(d)

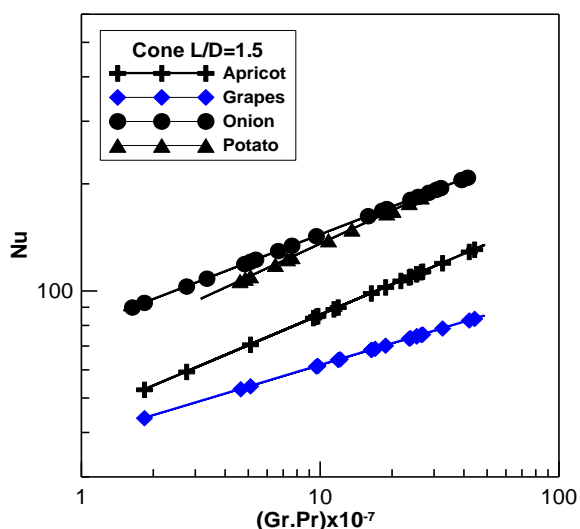

(e)

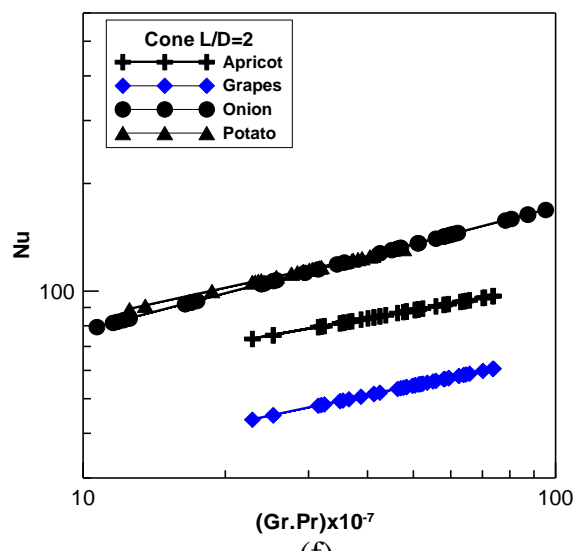

(f)

Fig. 3 The Nusselt number (Nu) versus the product of the Grashof and Prandtl numbers (Gr.Pr) for different products tested in the solar dryers 
Sh. Shams El-Din, M. Habib, A. El-Hanafy, Kh. Ramzy, "Evaluation of Convective Heat and ..."

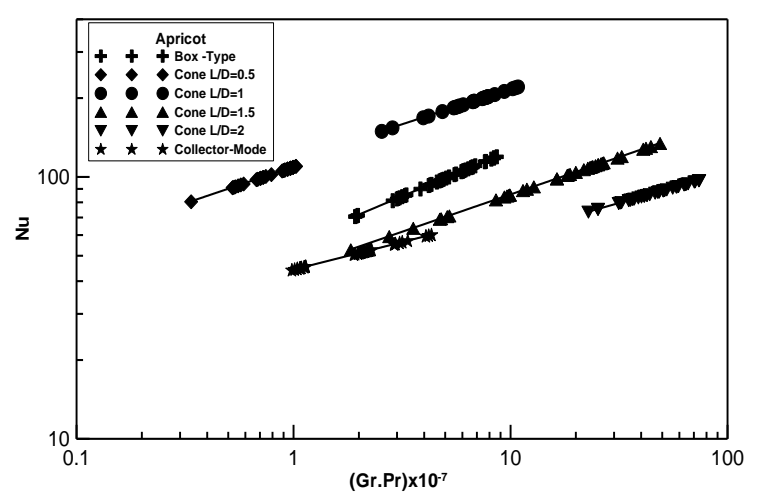

(a)

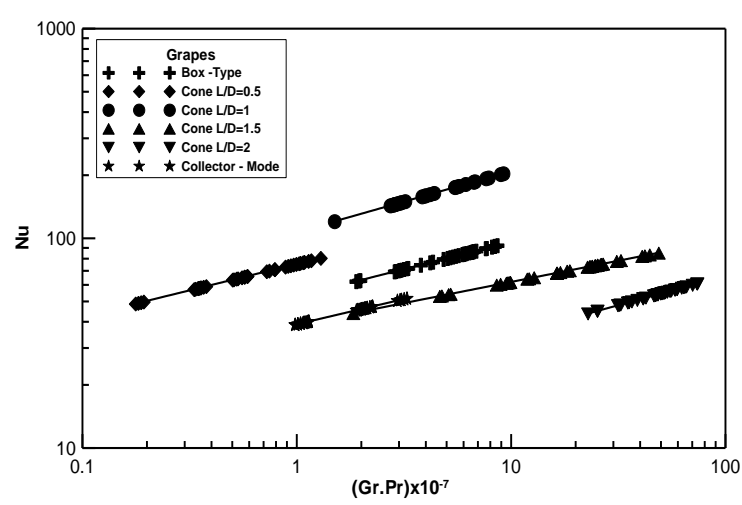

(b)

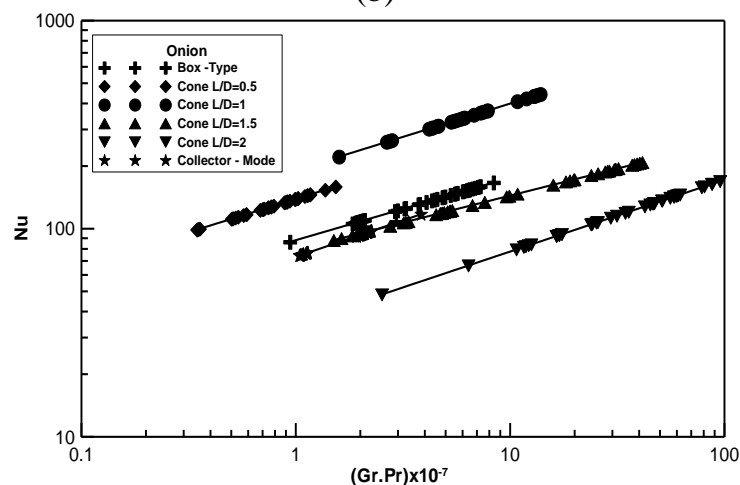

(c)

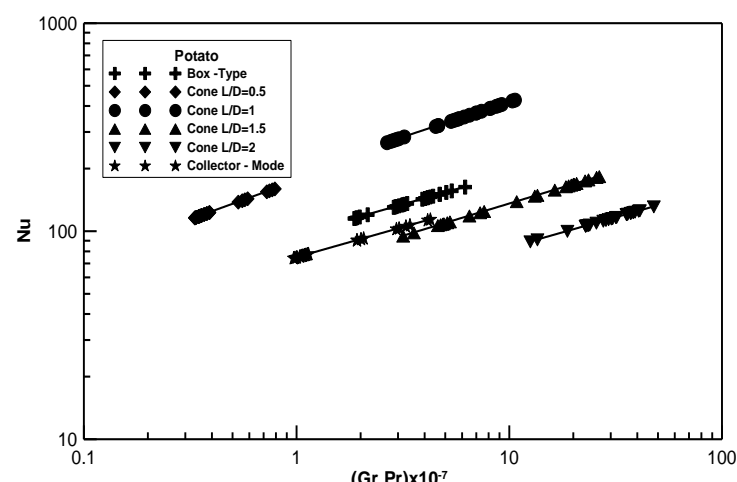

(d)

Fig.4 The Nusselt number $(\mathrm{Nu})$ versus the product of the Grashof and Prandtl numbers (Gr.Pr) for apricot, grapes, onion and potato in solar dryers

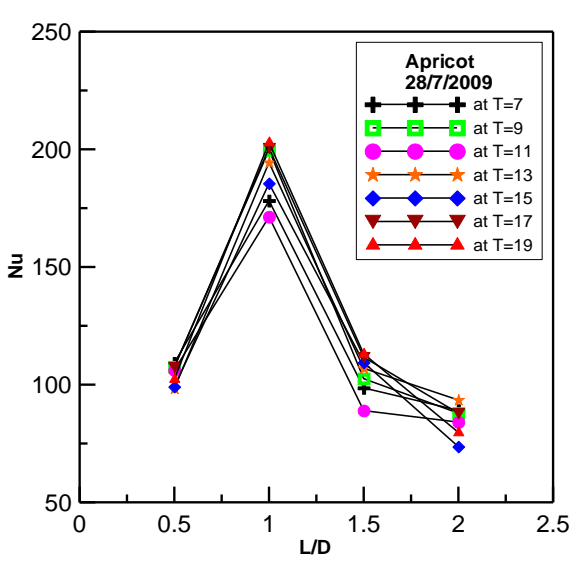

(a)

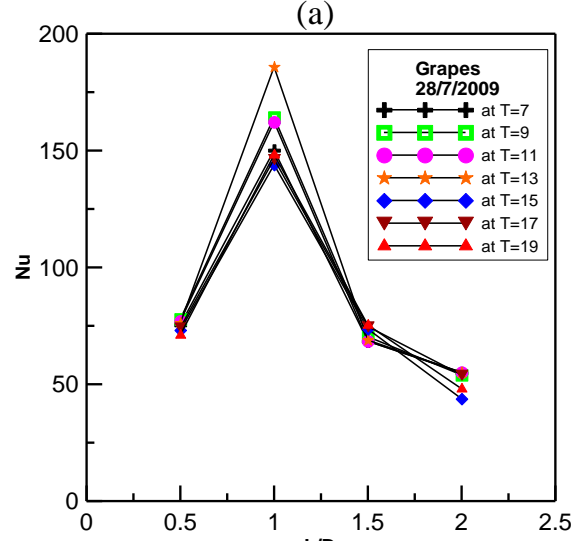

(b)
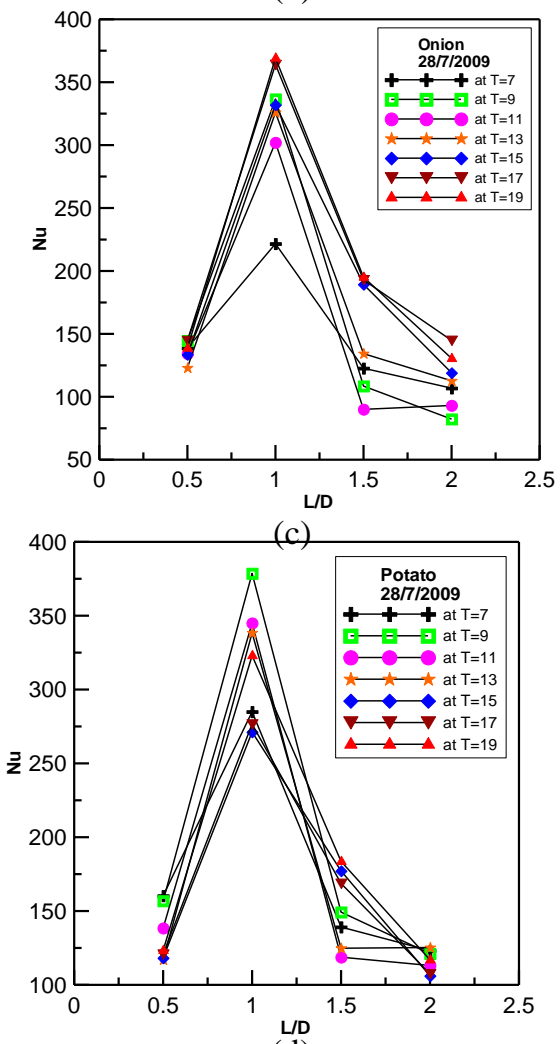

(d)

Fig. 5 The effect of L/D ratio on the Nusselt number for products at different drying time 
Sh. Shams El-Din, M. Habib, A. El-Hanafy, Kh. Ramzy, "Evaluation of Convective Heat and ..."

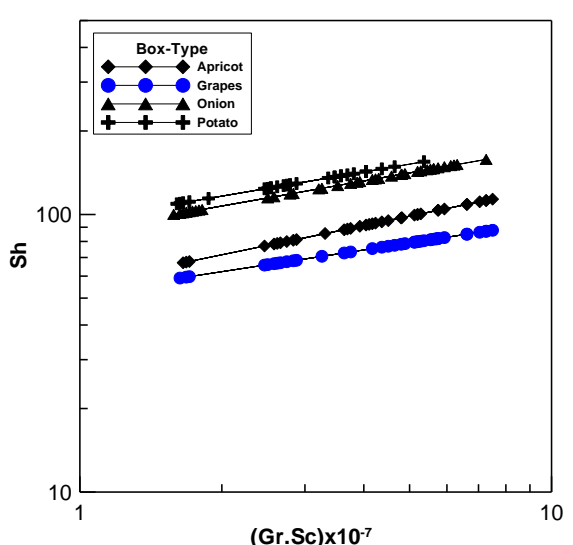

(a)

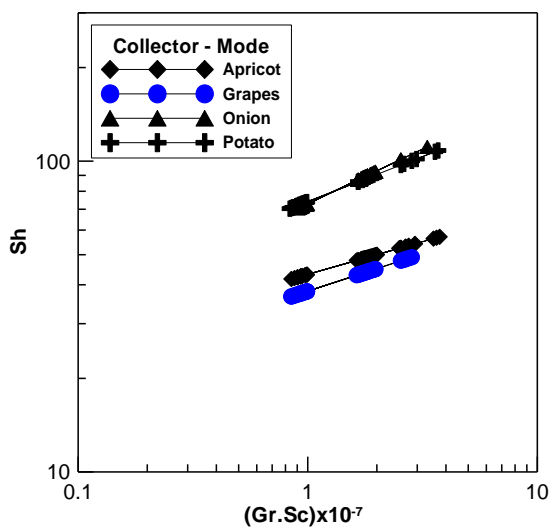

(b)

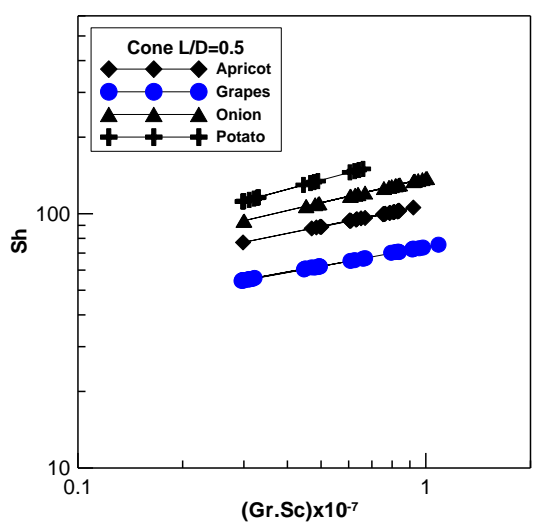

(c)

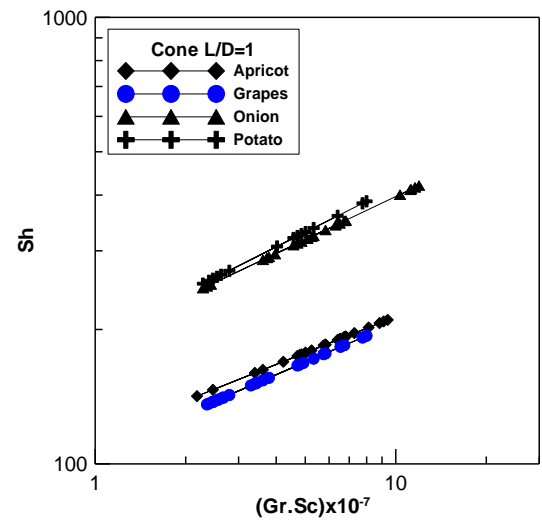

(d)

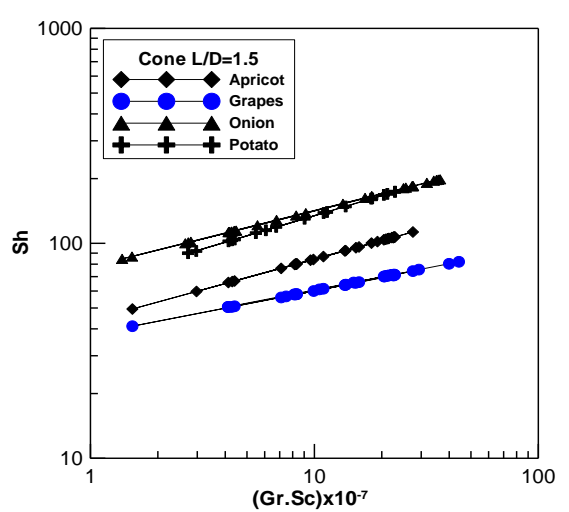

(e)

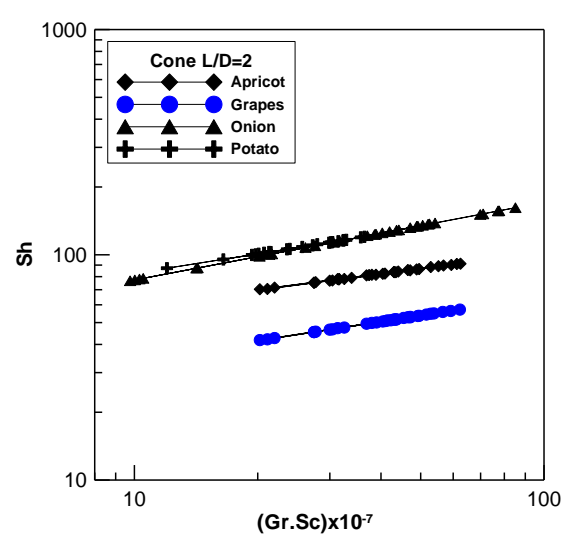

(f)

Fig. 6 The relation between the Sherwood number (Sh) and the product of the Grashof and Schmidt numbers $(\mathrm{Gr} . \mathrm{Sc})$ for solar dryers 
Sh. Shams El-Din, M. Habib, A. El-Hanafy, Kh. Ramzy, "Evaluation of Convective Heat and ..."

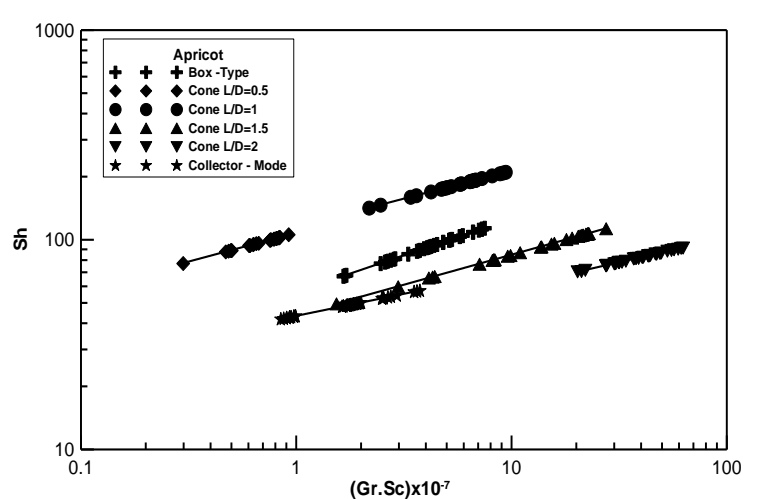

(a)

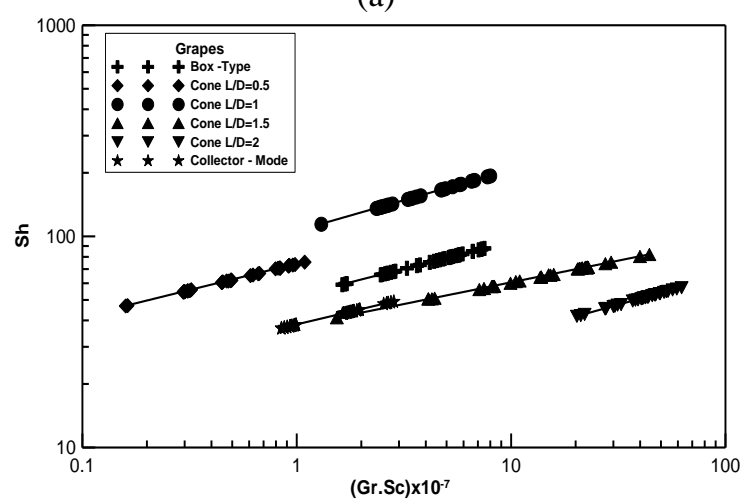

(b)

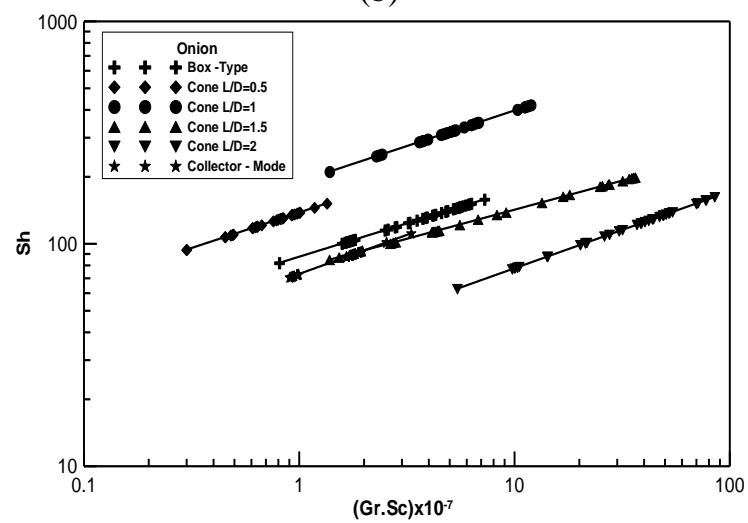

(c)

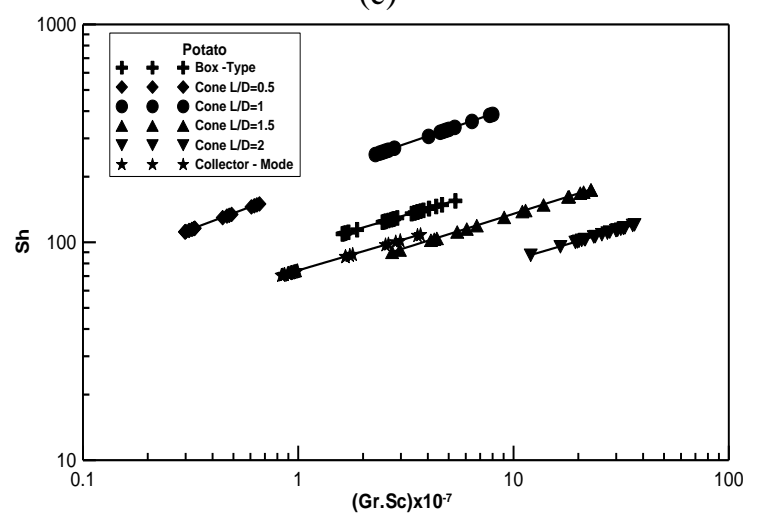

(d)

Fig. 7 The relation between the Sherwood number

(Sh) and the product of the Grashof and Schmidt numbers (Gr.Sc) for apricot, grapes, onion and potato in different solar dryers

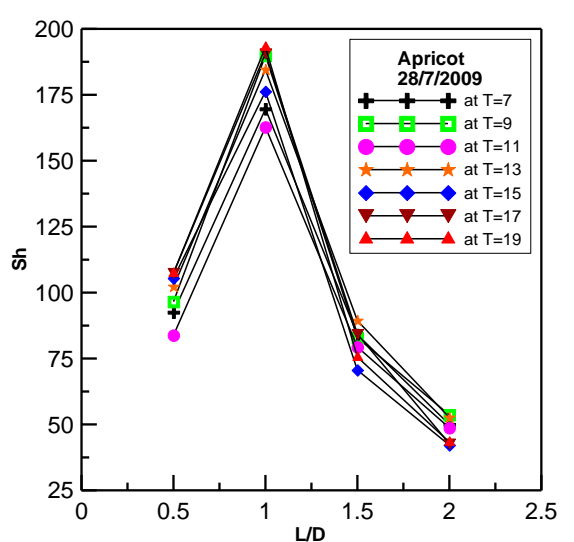

(a)

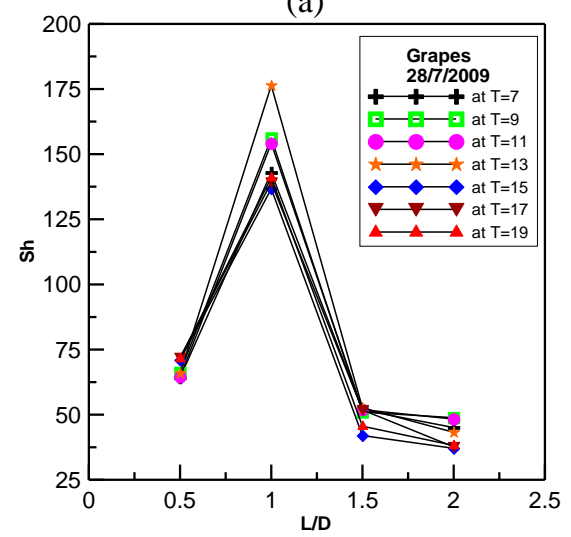

(b)

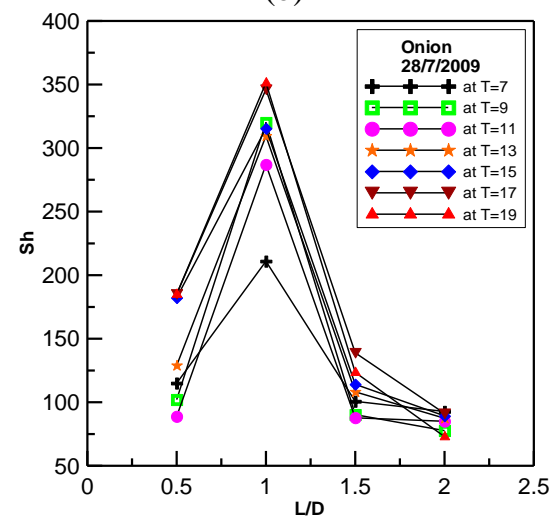

(c)

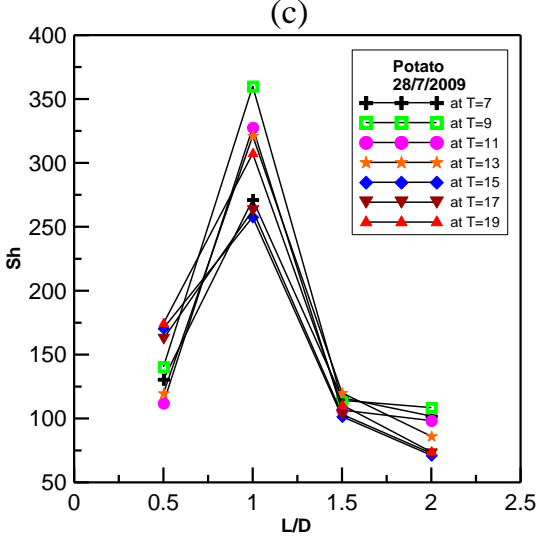

(d)

Fig. 8 The effect of L/D ratio on the Sherwood number for products at different drying times 
Sh. Shams El-Din, M. Habib, A. El-Hanafy, Kh. Ramzy, "Evaluation of Convective Heat and ..."

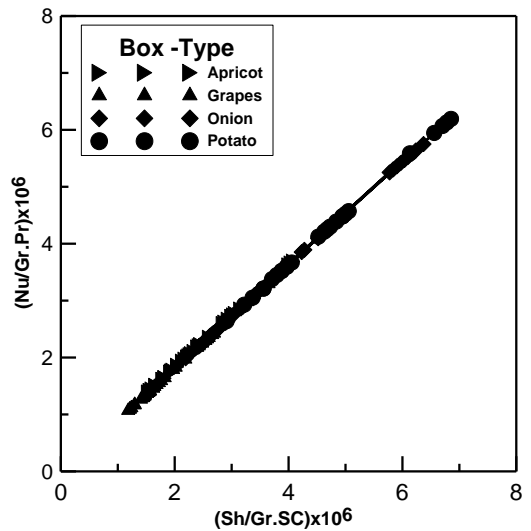

(a)

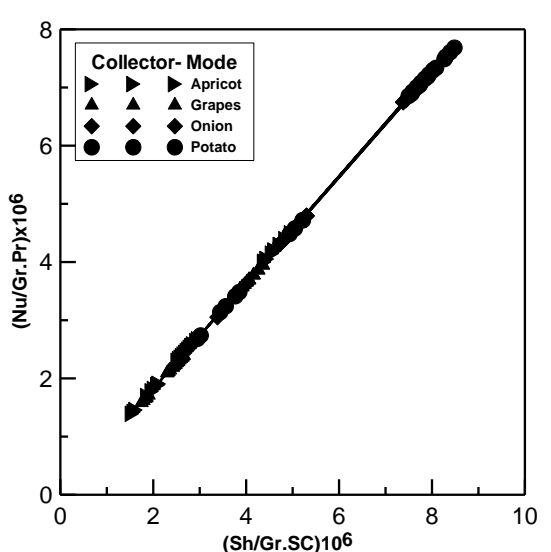

(b)

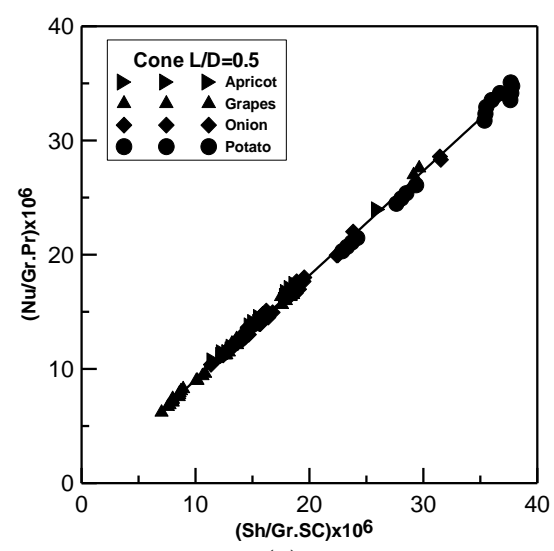

(c)

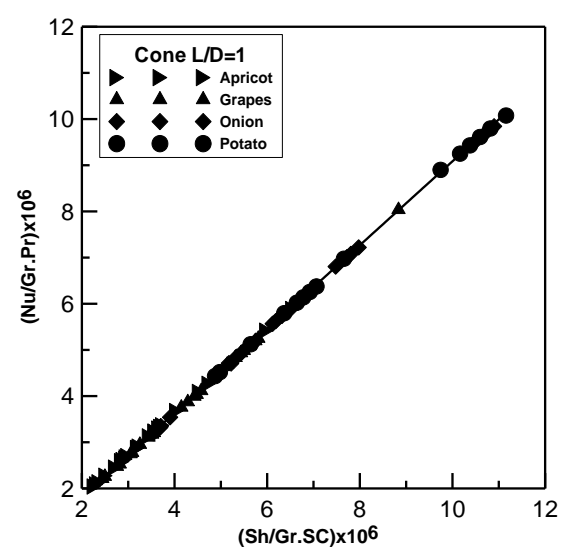

(d)

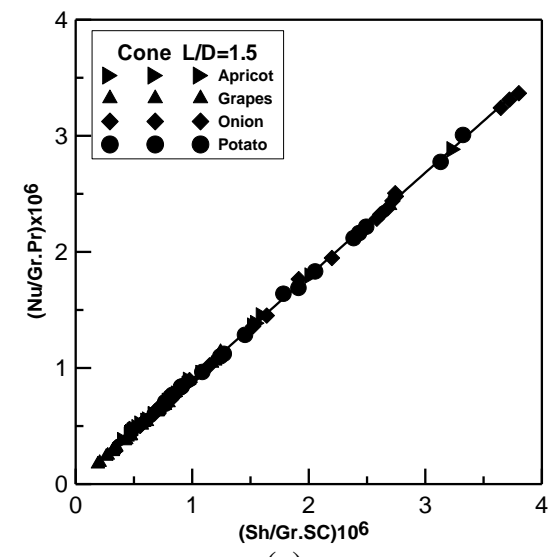

(e)

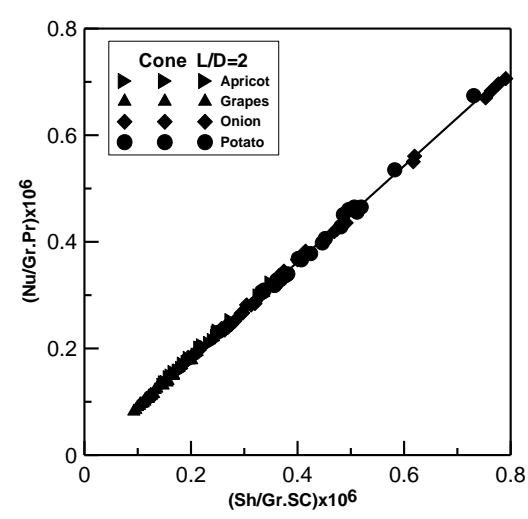

(f)

Fig. 9 The relation between the parameter $(\mathrm{Nu} / \mathrm{Gr}$. $\mathrm{Pr})$ and $(\mathrm{Sh} / \mathrm{Gr} . \mathrm{Sc})$ for different solar dryers 


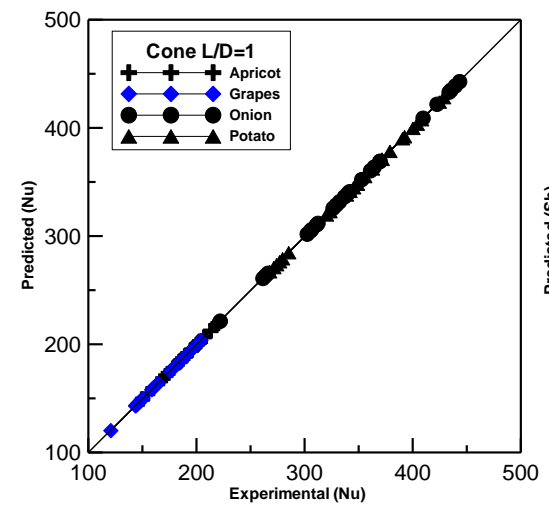

(a)

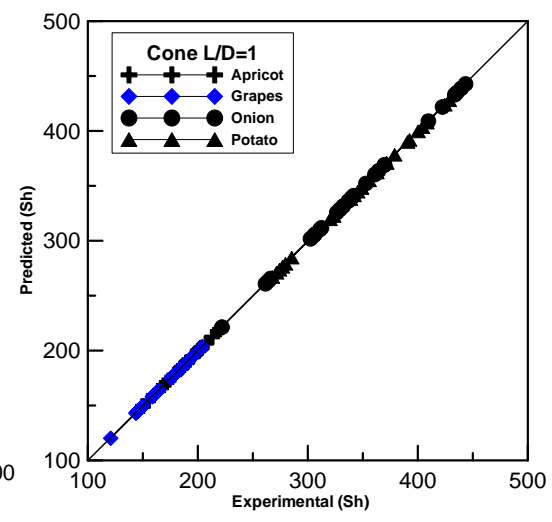

(b)

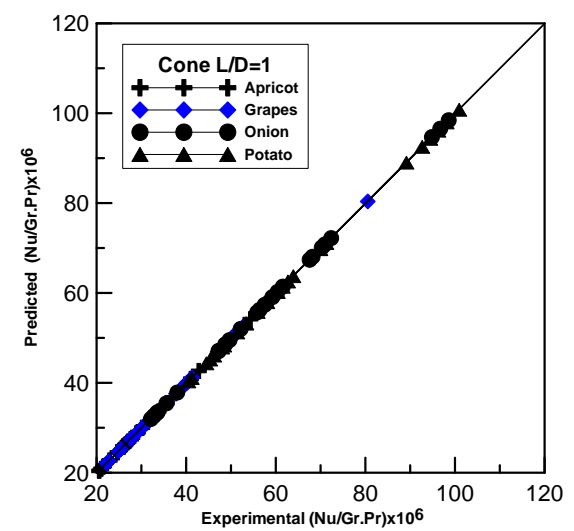

(c)

Fig. 10 Comparison of the predicted and experimental parameters; $(\mathrm{Nu}),(\mathrm{Sh})$ and $(\mathrm{Nu} / \mathrm{Gr} . \mathrm{Pr})$ by established model for solar conical dryer with $\mathrm{L} / \mathrm{D}=1$

Table 2, Heat and mass transfer results in drying units

\begin{tabular}{|c|c|c|c|c|c|c|c|}
\hline \multirow[t]{2}{*}{ Product } & \multirow[t]{2}{*}{ Parameter } & \multirow[t]{2}{*}{ Box-Type } & \multirow{2}{*}{$\begin{array}{l}\text { Collector } \\
\text { Mode }\end{array}$} & \multicolumn{4}{|c|}{ Conical Solar Dryer } \\
\hline & & & & $L / D=0.5$ & $L / D=1$ & $L / D=1.5$ & $L / D=2$ \\
\hline \multirow{6}{*}{ Apricot } & $\Delta T^{\prime}$ & $26-45$ & $26-42$ & $26-45$ & $26-50$ & $26-44.5$ & $26-44$ \\
\hline & $\mathbf{h}_{\mathrm{c}}$ & $3.8-5.9$ & $2.3-3.7$ & $27.8-36.8$ & $29-37$ & $5.5-4.4$ & $6.6-8.2$ \\
\hline & $\mathrm{Nu}$ & $81-119$ & $44-56$ & $80-109$ & $178-212$ & $52-118$ & $81-96$ \\
\hline & $\mathbf{h}_{\mathrm{m}}$ & $3-6$ & $2-3$ & $25-35$ & $5.7-10$ & $5.9-8.1$ & $26-35$ \\
\hline & Sh & $67-109$ & $41-53$ & $77-102$ & $142-208$ & $49-107$ & $75-91$ \\
\hline & $\mathbf{N u} / \mathbf{S h}$ & $1.09-1.20$ & $1.05-1.07$ & $1.03-1.06$ & $1.02-1.25$ & $1.06-1.10$ & $1.05-1.08$ \\
\hline \multirow{6}{*}{ Grapes } & $\Delta T^{\prime}$ & $26-47$ & $26-43$ & $26-45$ & $26-50$ & $26-44.5$ & $26-44$ \\
\hline & $\mathbf{h}_{\mathrm{c}}$ & $3.4-4.9$ & $2-2.9$ & $16.5-27.3$ & $24-33$ & $5.7-7.4$ & $3.7-5$ \\
\hline & Nu & $62-91$ & $38-51$ & $57-80$ & $143-186$ & $43-74$ & $43-60$ \\
\hline & $\mathbf{h}_{\mathrm{m}}$ & $3.2-4.7$ & $1.9-2.9$ & $18-25.7$ & $23-32$ & $3.9-7.1$ & $3.7-5$ \\
\hline & Sh & $65-87$ & $37-49$ & $54-73$ & $139-193$ & $50-71$ & $42-55$ \\
\hline & $\mathbf{N u} / \mathrm{Sh}$ & $0.95-1.04$ & $1.02-1.04$ & $1.05-1.09$ & $1.02-1.33$ & $0.86-1.04$ & $1.02-1.09$ \\
\hline \multirow{6}{*}{ Onion } & $\Delta T^{\prime}$ & $26-47$ & $26-43$ & $26-45$ & $26-50$ & $26-44.5$ & $26-44$ \\
\hline & $\mathbf{h}_{\mathrm{c}}$ & $5.8-8.5$ & $4-6.3$ & $34-49$ & $36-75$ & $8.5-17$ & $6.8-14$ \\
\hline & $\mathrm{Nu}$ & $107-159$ & $74-97$ & $98-145$ & $221-443$ & $88-208$ & $83-144$ \\
\hline & $\mathbf{h}_{\mathrm{m}}$ & $4.6-8.3$ & $3.7-6.3$ & $38-46$ & $34-74$ & $8-18.5$ & $5.2-13$ \\
\hline & Sh & $102-158$ & $71-101$ & $94-137$ & $210-420$ & $84-198$ & $62-162$ \\
\hline & $\mathrm{Nu} / \mathrm{Sh}$ & $1.006-1.04$ & $0.96-1.04$ & $1.04-1.05$ & $1.05-1.06$ & $1.04-1.05$ & $0.88-1.34$ \\
\hline \multirow{6}{*}{ Potato } & $\Delta T^{\prime}$ & $26-45$ & $26-43$ & $26-45$ & $26-50$ & $26-44.5$ & $26-44$ \\
\hline & $\mathbf{h}_{\mathrm{c}}$ & $6.3-8.8$ & $4-5.9$ & $40-53$ & $47-73$ & $9-16.5$ & $7.5-10.5$ \\
\hline & $\mathbf{N u}$ & $115-163$ & $74-114$ & $116-160$ & $284-448$ & $98-170$ & $89-123$ \\
\hline & $\mathbf{h}_{\mathbf{m}}$ & $6-8.4$ & $3.8-5.8$ & $40-52$ & $44-65$ & $8.8-15.8$ & $7.8-10.5$ \\
\hline & Sh & $110-155$ & $70-108$ & $112-150$ & $253-384$ & $90-170$ & $87-120$ \\
\hline & $\mathbf{N u} / \mathbf{S h}$ & $1.04-1.05$ & $1.05-1.06$ & $\begin{array}{ll}1.03 & 1.07\end{array}$ & $1.12-1.17$ & $1.0-1.09$ & $1.03-1.13$ \\
\hline
\end{tabular}


Sh. Shams El-Din, M. Habib, A. El-Hanafy, Kh. Ramzy, "Evaluation of Convective Heat and ..."

Table 3, Values of $\mathrm{C}, \mathrm{n}$ and $\mathrm{R}^{2}$ for different products dried in the tested solar unites

\begin{tabular}{|c|c|c|c|c|c|c|c|c|c|c|c|c|}
\hline \multirow{2}{*}{$\begin{array}{c}\text { Types of solar } \\
\text { dryers }\end{array}$} & \multicolumn{3}{|c|}{ Apricot } & \multicolumn{3}{|c|}{ Grapes } & \multicolumn{3}{|c|}{ Onion } & \multicolumn{3}{|c|}{ Potato } \\
\hline & $\mathrm{C}$ & $\mathrm{n}$ & $\mathrm{R}^{2}$ & $\mathrm{C}$ & $\mathrm{n}$ & $\mathrm{R}^{2}$ & $\mathrm{C}$ & $\mathrm{n}$ & $\mathrm{R}^{2}$ & $\mathrm{C}$ & $\mathrm{n}$ & $\mathrm{R}^{2}$ \\
\hline Box-type & 0.2 & 0.35 & 0.99 & 0.8 & 0.26 & 0.99 & 0.7 & 0.3 & 0.99 & 0.9 & 0.29 & 0.99 \\
\hline Collector mode & 1.5 & 0.21 & 0.99 & 0.8 & 0.24 & 0.99 & 0.26 & 0.35 & 0.99 & 0.7 & 0.29 & 1 \\
\hline Cone $L / D=0.5$ & 1.2 & 0.28 & 0.99 & 1.3 & 0.25 & 1 & 0.8 & 0.32 & 0.99 & 0.45 & 0.37 & 1 \\
\hline Cone $L / D=1$ & 1.5 & 0.27 & 1 & 1 & 0.29 & 1 & 1.1 & 0.32 & 1 & 0.8 & 0.34 & 0.99 \\
\hline Cone $\mathrm{L} / \mathrm{D}=1.5$ & 0.45 & 0.28 & 0.99 & 1.5 & 0.20 & 0.99 & 1.2 & 0.26 & 0.99 & 0.45 & 0.31 & 1 \\
\hline Cone $L / D=2$ & 0.8 & 0.23 & 1 & 0.2 & 0.28 & 1 & 0.13 & 0.34 & 0.99 & 0.4 & 0.29 & 0.99 \\
\hline Cone $\mathrm{L} / \mathrm{D}=2$ & 0.8 & 0.23 & 1 & 0.2 & 0.28 & 1 & 0.13 & 0.34 & 0.99 & 0.4 & 0.29 & 0.99 \\
\hline \multirow{2}{*}{$\begin{array}{c}\text { Types of solar } \\
\text { dryers }\end{array}$} & \multicolumn{3}{|c|}{ Apricot } & \multicolumn{3}{|c|}{ Grapes } & \multicolumn{3}{|c|}{ Onion } & \multicolumn{3}{|c|}{ Potato } \\
\hline & $\mathrm{C}^{\prime}$ & $\mathrm{n}^{\prime}$ & $\mathrm{R}^{2}$ & $\mathrm{C}^{\prime}$ & $\mathrm{n}^{\prime}$ & $\mathrm{R}^{2}$ & $\mathrm{C}^{\prime}$ & $\mathrm{n}^{\prime}$ & $\mathrm{R}^{2}$ & $\mathrm{C}^{\prime}$ & $\mathrm{n}^{\prime}$ & $\mathrm{R}^{2}$ \\
\hline Box-type & 0.21 & 0.34 & 0.99 & 0.81 & 0.25 & 0.99 & 0.69 & 0.29 & 1 & 0.93 & 0.28 & 1 \\
\hline Collector mode & 1.48 & 0.22 & 0.99 & 0.81 & 0.23 & 0.99 & 0.26 & 0.35 & 0.99 & 0.72 & 0.29 & 0.99 \\
\hline Cone $\mathrm{L} / \mathrm{D}=0.5$ & 1.23 & 0.27 & 0.99 & 1.33 & 0.25 & 1 & 0.79 & 0.31 & 0.99 & 0.45 & 0.37 & 0.99 \\
\hline Cone $\mathrm{L} / \mathrm{D}=1$ & 1.48 & 0.26 & 1 & 1.08 & 0.28 & 0.99 & 1.09 & 0.31 & 1 & 0.82 & 0.33 & 1 \\
\hline Cone $L / D=1.5$ & 0.44 & 0.28 & 1 & 1.52 & 0.22 & 1 & 1.21 & 0.26 & 0.99 & 0.44 & 0.31 & 0.99 \\
\hline Cone $\mathrm{L} / \mathrm{D}=2$ & 0.79 & 0.23 & 0.99 & 0.20 & 0.28 & 1 & 0.13 & 0.34 & 1 & 0.41 & 0.28 & 1 \\
\hline
\end{tabular}

Table 4, Values of $C^{\prime}, n^{\prime}$ and $R^{2}$ for different products dried in the tested solar unites

\begin{tabular}{|c|c|c|c|c|c|c|c|}
\hline \multirow[t]{2}{*}{ Product } & \multirow[t]{2}{*}{ Parameter } & \multirow[t]{2}{*}{ Box-Type } & \multirow{2}{*}{$\begin{array}{c}\text { Collector } \\
\text { Mode }\end{array}$} & \multicolumn{4}{|c|}{ Conical Solar Dryer } \\
\hline & & & & $L / D=0.5$ & $\mathrm{~L} / \mathrm{D}=\mathbf{1}$ & $L / D=1.5$ & $L / D=2$ \\
\hline \multirow{6}{*}{ Apricot } & $\Delta T^{\prime}$ & $26-45$ & $26-42$ & $26-45$ & $26-50$ & $26-44.5$ & $26-44$ \\
\hline & $\mathbf{h}_{\mathbf{c}}$ & $3.8-5.9$ & $2.3-3.7$ & $27.8-36.8$ & $29-37$ & $5.5-4.4$ & $6.6-8.2$ \\
\hline & Nu & $81-119$ & $44-56$ & $80-109$ & $178-212$ & $52-118$ & $81-96$ \\
\hline & $\mathbf{h}_{\mathrm{m}}$ & $3-6$ & $2-3$ & $25-35$ & $5.7-10$ & $5.9-8.1$ & $26-35$ \\
\hline & Sh & $67-109$ & $41-53$ & $77-102$ & $142-208$ & $49-107$ & $75-91$ \\
\hline & Nu/Sh & $1.09-1.20$ & $1.05-1.07$ & $1.03-1.06$ & $1.02-1.25$ & $1.06-1.10$ & $1.05-1.08$ \\
\hline \multirow{6}{*}{ Grapes } & $\Delta T$ & $26-47$ & $26-43$ & $26-45$ & $26-50$ & $26-44.5$ & $26-44$ \\
\hline & $\mathbf{h}_{\mathrm{c}}$ & $3.4-4.9$ & $2-2.9$ & $16.5-27.3$ & $24-33$ & $5.7-7.4$ & $3.7-5$ \\
\hline & $\mathrm{Nu}$ & $62-91$ & $38-51$ & $57-80$ & $143-186$ & $43-74$ & $43-60$ \\
\hline & $\mathbf{h}_{\mathrm{m}}$ & $3.2-4.7$ & $1.9-2.9$ & $18-25.7$ & $23-32$ & $3.9-7.1$ & $3.7-5$ \\
\hline & Sh & $65-87$ & $37-49$ & $54-73$ & $139-193$ & $50-71$ & $42-55$ \\
\hline & $\mathrm{Nu} / \mathrm{Sh}$ & $0.95-1.04$ & $1.02-1.04$ & $1.05-1.09$ & $1.02-1.33$ & $0.86-1.04$ & 1.02- 1.09 \\
\hline \multirow{6}{*}{ Onion } & $\Delta T^{\prime}$ & $26-47$ & $26-43$ & $26-45$ & $26-50$ & $26-44.5$ & $26-44$ \\
\hline & $\mathbf{h}_{\mathrm{c}}$ & $5.8-8.5$ & $4-6.3$ & $34-49$ & $36-75$ & $8.5-17$ & $6.8-14$ \\
\hline & $\mathrm{Nu}$ & $107-159$ & $74-97$ & $98-145$ & $221-443$ & $88-208$ & $83-144$ \\
\hline & $\mathbf{h}_{\mathrm{m}}$ & $4.6-8.3$ & $3.7-6.3$ & $38-46$ & $34-74$ & $8-18.5$ & $5.2-13$ \\
\hline & Sh & $102-158$ & $71-101$ & $94-137$ & $210-420$ & $84-198$ & $62-162$ \\
\hline & Nu/Sh & $1.006-1.04$ & $0.96-1.04$ & $1.04-1.05$ & $1.05-1.06$ & $1.04-1.05$ & $0.88-1.34$ \\
\hline \multirow{6}{*}{ Potato } & $\Delta T^{\prime}$ & $26-45$ & $26-43$ & $26-45$ & $26-50$ & $26-44.5$ & $26-44$ \\
\hline & $\mathbf{h}_{\mathbf{c}}$ & $6.3-8.8$ & $4-5.9$ & $40-53$ & $47-73$ & $9-16.5$ & $7.5-10.5$ \\
\hline & Nu & $115-163$ & $74-114$ & $116-160$ & $284-448$ & $98-170$ & $89-123$ \\
\hline & $\mathbf{h}_{\mathbf{m}}$ & $6-8.4$ & $3.8-5.8$ & $40-52$ & $44-65$ & $8.8-15.8$ & $7.8-10.5$ \\
\hline & Sh & $110-155$ & $70-108$ & $112-150$ & $253-384$ & $90-170$ & $87-120$ \\
\hline & $\mathbf{N u} / \mathbf{S h}$ & $1.04-1.05$ & $1.05-1.06$ & 1.031 .07 & $1.12-1.17$ & $1.0-1.09$ & $1.03-1.13$ \\
\hline
\end{tabular}


Sh. Shams El-Din, M. Habib, A. El-Hanafy, Kh. Ramzy, "Evaluation of Convective Heat and ..."

Table 5, the proposed empirical correlations for describing the analogy between heat and mass transfer for different tested solar dryers

\begin{tabular}{|c|c|c|c|c|c|c|}
\hline No & Solar Dryer & Empirical Corr & relations & $\mathbf{R}^{2}$ & $\begin{array}{c}\text { Gr.Pr } \\
\text { Range x10 }^{-7}\end{array}$ & $\begin{array}{c}\text { Gr.Sc } \\
{\text { Range } \times 10^{-7}}^{-7}\end{array}$ \\
\hline 1 & Box-type & $\left(\frac{N u}{G r \cdot \operatorname{Pr}}\right)=0.9106$ & $\left(\frac{S h}{G r \cdot S c}\right)^{0.999}$ & $\begin{array}{c}\cdot, 999 \\
9\end{array}$ & $1.88-8.61$ & $1.65-7.48$ \\
\hline$r$ & $\begin{array}{l}\text { Collector- } \\
\text { mode }\end{array}$ & $\left(\frac{N u}{G r \cdot \operatorname{Pr}}\right)=0.9107$ & $\left(\frac{S h}{G r \cdot S c}\right)^{1.001}$ & $\begin{array}{c}\cdot, 999 \\
9\end{array}$ & $0.98-3.15$ & $0.85-3.68$ \\
\hline$r$ & $\begin{array}{c}\text { Cone, } \\
\mathrm{L} / \mathrm{D}=0.5\end{array}$ & $\left(\frac{N u}{G r . \operatorname{Pr}}\right)=0.8978$ & $\left(\frac{S h}{G r \cdot S c}\right)^{1.004}$ & $\begin{array}{c}\cdot, 99 \vee \\
\wedge\end{array}$ & $0.34-1.16$ & $0.29-1.08$ \\
\hline$\varepsilon$ & $\begin{array}{l}\text { Cone, } \\
\mathrm{L} / \mathrm{D}=1\end{array}$ & $\left(\frac{N u}{G r \cdot \operatorname{Pr}}\right)=0.9088$ & $\left(\frac{S h}{G r \cdot S c}\right)^{0.999}$ & $\begin{array}{c}\cdot, 999 \\
9\end{array}$ & $1.49-13.83$ & $2.34-11.91$ \\
\hline 0 & $\begin{array}{c}\text { Cone, } \\
\text { L/D=1.5 }\end{array}$ & $\left(\frac{N u}{G r \cdot \operatorname{Pr}}\right)=0.9126$ & $\left(\frac{S h}{G r . S c}\right)^{0.9875}$ & $\begin{array}{c}\cdot, 911 \\
9\end{array}$ & $1.5-48.66$ & $1.37-34.97$ \\
\hline 7 & $\begin{array}{l}\text { Cone, } \\
\mathrm{L} / \mathrm{D}=2\end{array}$ & $\left(\frac{N u}{G r \cdot \operatorname{Pr}}\right)=0.9043$ & $\left(\frac{S h}{G r \cdot S c}\right)^{0.9972}$ & $\cdot \stackrel{., 999}{r}$ & $11.5-95.14$ & $10-62.41$ \\
\hline
\end{tabular}

